LASER-ZONE GROWTH IN A RIBBON-TO-RIBBON (RTR) PROCESS

SILICON SHEET GROWTH DEVELOPMENT FOR THE LARGE AREA SILICON SHEET TASK OF THE LOW-COST SOLAR ARRAY PROJECT

Annual Report, October 1, 1977-September 30, 1978

By

A. Baghdadi

R. W. Gurtler

R. Legge

B. Sopori

R. J. Ellis

DOE/JPL/954376-7

Work Performed Under Contract No. NAS-7-100-954376

Semiconductor Group

Motorola, Inc.

Phoenix, Arizona

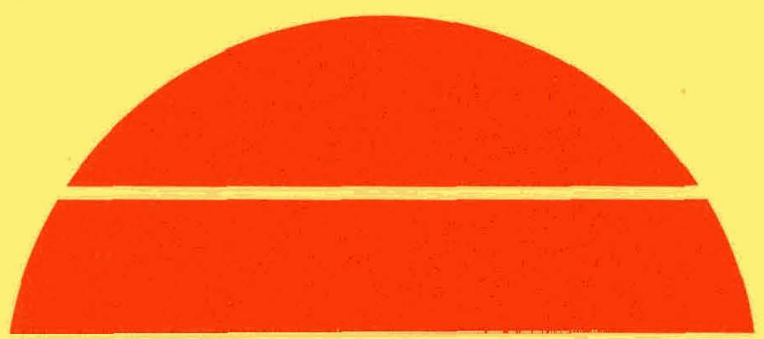

\title{
MASTER
}

\section{U.S. Department of Energy}

obsumb En

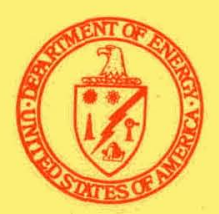




\section{DISCLAIMER}

This report was prepared as an account of work sponsored by an agency of the United States Government. Neither the United States Government nor any agency Thereof, nor any of their employees, makes any warranty, express or implied, or assumes any legal liability or responsibility for the accuracy, completeness, or usefulness of any information, apparatus, product, or process disclosed, or represents that its use would not infringe privately owned rights. Reference herein to any specific commercial product, process, or service by trade name, trademark, manufacturer, or otherwise does not necessarily constitute or imply its endorsement, recommendation, or favoring by the United States Government or any agency thereof. The views and opinions of authors expressed herein do not necessarily state or reflect those of the United States Government or any agency thereof. 


\section{DISCLAIMER}

Portions of this document may be illegible in electronic image products. Images are produced from the best available original document. 


\section{NOTICE}

This report was prepared as an account of work sponsored by the United States Government. Neither the United States nor the United States Department of Energy, nur any of their employees, nor any of their contractors, subcontractors, or their employees, makes any warranty, express or implied, or assumes any legal liability or responsibility for the accuracy, completeness or usefulness of any information. apparatus, product or process disclosed, or represents that its use would not infringe privately owned rights.

This report has been reproduced directly from the best available copy.

Available from the National Technical Information Service, U. S. Department of Commerce, Springfield, Virginia 22161.

Price: Paper Copy $\$ 6.00$

Microfiche $\$ 3.00$ 


\title{
LASER-ZZNE . GROWTH. IN A RIBBON-TO-RIBBON (RTR) PROCESS
}

SILICON SHEET GROWTH DEVELOPMENT FOR THE LARGE AREA SILICON SHEET. TASK OF THE LOW-COST SOLAR ARRAY PROJECT

\author{
ANNUAL REPORT
}

'MOTOROLA REPORT NO. $2256 / 11$

1 OCTOBER 1977 - 30 SEPTEMBER 1978

JPL CONTRACT NO. 954376

BY

This report wOTICE

was prepared as an account of work sponsored by the United States Covernment. Neither the United States nor the United States Department of contractors, subcontractors, or their employees, makes any warranty, express or implied, or assumes any legal liability or responsibility for the accuracy, comple teness or usefulness of any information, apparalus, product or process disclosed, or represents that its use would not infringe privately owned rights.

A. BAGHDADI, R. W. GURTLER, R: LEGGE, B. SOPORI, R.J. ELLIS PREPARED BY

\author{
MOTOROLA, INC. \\ SEM! :ONDUCTOR GROUP \\ 5:: E. MCDOWELL ROAD \\ PHUENIX, ARIZONA 85008
}

THE JPL LOW-COST SOLAR ARRAY PROJECT IS SPONSORED BY THE U.S. DEPARTMENT OF ENERGY AND FORMS PART OF THE SOLAR PHOTOVOLTAIC CONVERSION PROGRAM TO INITIATE A MAJOR. EFFORT TOWARD THE DEVELOPMENT OF LOW-COST SOLAR ARRAYS. THIS WORK WAS PERFORMED FOR THE JET P.ROPULSION LABORATORY, CALIFORNIA INSTITUTE OF TECHNOLOGY BY AGREEMENT BETWEEN NASA AND DOE. 


\section{SU MMARY}

This report includes a new calculation of the effects of thermal stresses during growth on silicon ribbon quality. Thermal stress distributions are computed for ribbon.growth under a variety of temperature profiles. It is shown that the width dependence is not as large as had previously been assumed. Undor practisal grnwth conditions, the stresses are actually oflen below the yield point. It is also shown that, for the thermal profiles presently in use, buckling is probable for widths greater than $4-6 \mathrm{~cm}$. Two "ideal" temperature profiles are described which could result in rlbbons grown without either high dislocation generation or buckling.

We have now achieved a growth rate of $55 \mathrm{~cm}^{2} / \mathrm{min}$ with a single ribuon. We have also demonstrated the growth of RTR ribbon with a fairly uniform parallel dendritic structure. The microstructure of this ribbon concentrates the most damaging defects into small areas between dendrites. This microstructure could result in an improved overall efficiency for cells fabricated on RTR ribbon. We have obtained encouraging results with two approaches for reducing the Mo impurity. level in polycrystalline feedstock. Neutron Activation Analysis has shown that the no level can be reduced to below the level of detection by etching the polycrystalline ribbon surface. Coating the Mo substrate with $\mathrm{Si}_{3} \mathrm{~N}_{4}$ does not affect thermal shear separation of the polyribbon $\left(\mathrm{Si}_{3} \mathrm{~N}_{4}\right.$ is. a well-known diffusion barrierl; this process shows promise of improving cell efticiencies and also increasing the useful lifo of the molybdenum sibstrate.

A number of solar cells have been fabricated on RTR silicon grown from CVD feedstock. The highest efficiency $(n-6 \%)$ was obtained on a sample grown from a polyribbon deposited on a $\mathrm{Si}_{3} \mathrm{~N}_{4}$ coated Nio substrate. This 
result is disappointing. It may be due to incomplete coverage of the Mo substrate. We are now working with more uniform $\mathrm{Si}_{3} \mathrm{~N}_{4}$ films of increased thickness. 


\section{TABLE OF CONTENTS}

\section{SECTION}

TITLE

PAGE

i.o

Thermal Stress Analysis

1.1

The Model

1.2

Theoretical

7

1.3

Numerical Solution

1.4

Stress Distribution

10

1.4 .1

Pure Parabolic

1.4 .2

Limited-Extent Parabolic

1.4 .3

Free-End Promimity Effects

Realistic Temperature Proflles 
8.1

Polycrystall ine Feedstock

72

8.2

RTR Growth

72

8.3

Solar Cell Processing

72

9.0

New Technology

74 


\section{LIST OF FIGURES}

$5 \mathrm{~cm} / \mathrm{min}$. Signlficant buckling is evident.

Sample geometry for theoretical analysis.

Mesh definition for numerical analysis. $K$

and $K_{y}$ are integers which increase the density of the mesh for the distance $5 x$ to glve improvend arrouracy and where large variations in temperature occur. sample with the temperature profile T5 of Figure 7.

The parabolic-linear transitions are noted for each profile.

Stress distributions for a $2 \mathrm{~cm}$ wide sample with the various temperature profiles of Figure 5 .

Linear-parabolic-linear temperature profiles imposed at varlous locations with respect to d liee end. The rosulting stress distributions are shuwn in rigure 8.

Stress distributions resulting from a Il nearparabolic-linear temperature profile imposed at various distances from the free end (melt) of a $2 \mathrm{~cm}$ wide ribbon.

Width dependence of stresses resultiriy ficiii a parabolic-linear temperature profile (T5 of Figure 7) imposed near the free end (melt) uf a ribbon.

A "real" ribbon growth temperature profile is a composite of a laser-only (theoretical) and furnace-only (measured) profile. Also shown is a linearized version of the compusite profile which simplified the numerical analysis.

the influence of (a) a laser-only profile, (b) a furnace-only profile and (c) a composite profile which might be typical of actual growth conditions. 
Width dependence of stresses in a ribbon with the composite temperature profile of Figure 10.

"Ideal" profile exhibiting a perfectly linear

distribution from the melt down to a temperature of $600^{\circ} \mathrm{C}$; then parabol ical ly approaching an ambient temperature of $100^{\circ} \mathrm{C}$.

Stress distributions arising from the "ideal" profile of. Figure 13. For wide samples, very large stresses result.

Profile improvements which can lead to improved, wide ribbon growth conditions. T2 represents conditions expected when the melt is moved closer to the postheater. T3 represents an ideal profile which achleves high growth velocity and low stresses (see Figure 16).

CVD ribbon: The black dots are the nodules containing the growth spikes referred to in the text.

19a RTR sample grown from feedstock containing growth spikes.

RTR sample grown from feedstock which did not contain growth splkes. growth. 
Microcrack in $\mathrm{Si}_{3} \mathrm{~N}_{4}$ flim (400X magnification). 56

29 Diffusion length measurement by DWM - Sample 59 784-1.

30. Semilogarithmic current-voltage characteristics--regrown single crystal and CVD cells.

31 Ribbon fracture -- parallel to growth. 65

31b. Ribbon fracture -- normal lo growth. 65 


\subsection{THERMAL STRESS ANALYSIS}

In the evolution of current ribbon crystal growth technologies, the role of thermally induced stresses has been one of a major antagonist. In early stages of development, fracture due to residual stresses arising from thermal non-linearities near the growth interface, led to severe limitations for growth velocity and ribbon width. With the addition of well designed postheaters (and in the case of RTR growth, preheaters) residual stresses have been all but eliminated [1]. This is not to say, however, that thermal stresses near the growth interface have been el iminated; all that has been achieved is relief of built-in stresses as the ribbon passes through the postheater. Substantial thermal stresses remain throughout the growth region and their presence is manifested in the generation of dislocations and ribbon buckling. Dislocations can lead to reductions in minority carrier lifetime [2] which can result in low photovoltaic efficiencies. Buckling (see Figure 1) leads to difficulties in automated processing of ribbons, e.g., transport mechanisms, photolithography, etc.

Because of these adverse effects, it is of importance to have a better understanding of the nature of thermal stresses in a ribbon growth environment. One study of this type has already been reported by Surek [3]. In that paper, an analytic treatment was presented; it was not actually appropriate, as was pointed out in the paper. Nevertheless, some general trends indicated from that analysis implied that stress levels would increase very rapidly with sample width. To remedy the deficiencies of the analytical treatment, a numerical solution which confirmed the deficiencies of the analytic treatment was also described. However, no data were presented from the numerical approach. A more 

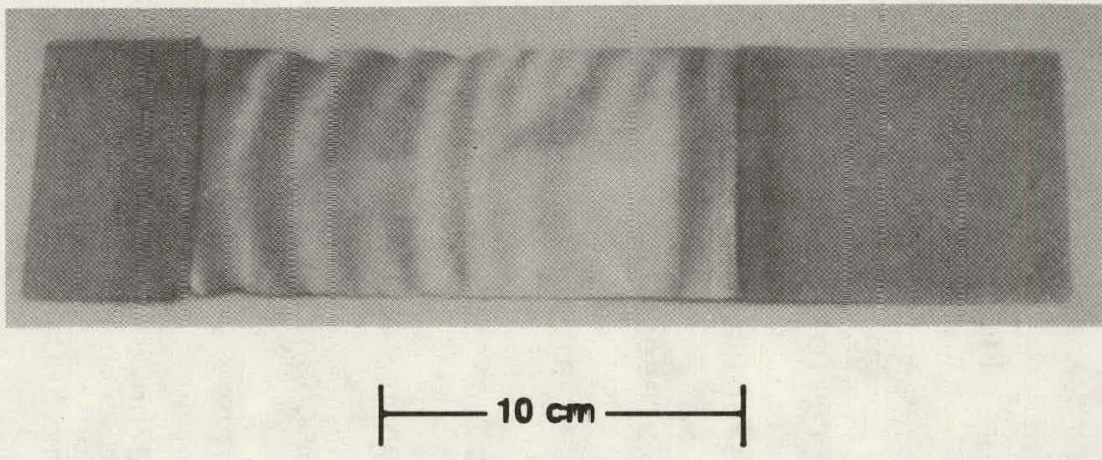

E8743

FIGURE 1: Fhotograph of $7.5 \mathrm{~cm}$ wide RTR ribbon grown at $5 \mathrm{~cm} / \mathrm{min}$. Significant buckling is evident. 
complete study of this type is useful. to ascertain the effects of variations In thermal profile and ribbon width on induced stresses. In this manner, better postheater design criterla may be evolved which might minimize or eliminate these stresses. In the case of RTR growth, almost any physically sensible thermal profile is achievable. Is it possible then to achieve high growth throughput and arbitrarily low stresses simultaneously? The answer to this question is a qualified affirmative. Numerical solutions to stress distributions arising in ribbons of various widths, with various thermal profiles, have been obtained. First, very simple hypothetical temperature profiles are studied in some detail to clearly emphasize the impact of a free boundary, and ribbon width, on resulting stresses. Then some realistic thermal profiles are studied to indicate the stress fields which are typical of present day growth environments. Next, consideration is given to various idealized thermal profiles which offer significant promise. Finally, the phenomenon of ribbon buckling is discussed in connection with the stress distributions presented.

\subsection{THE MODEL}

In this study, the ribbon has been supposed to be perfectly elastic, even adjacent to the molten zone. This immediately brings into question the usefulness of the study since silicon becomes plastic, or more correctly, viscoelastic, at elevated temperatures and therefore some degree of stress relief will occur which should be accounted for. Surek [ 3 ] has indicated that stress relief should occur very rapidly and completely for temperatures above $1200^{\circ} \mathrm{C}$. There is some question; however, as to the 
effectiveness of stress relief, especlally near the melt zone, towards reduction of stresses. Stress relief is a dynamic process and in the immedlate vicinity of the melt, stresses are rapldily changing. As will be shown, for a wide sample (e.g. $6 \mathrm{~cm}$ wide) at growth velocities of 8 $\mathrm{cm} / \mathrm{m} \cdot \mathrm{in}$, elastic strain rates of $10^{-5} \mathrm{sec}^{-1}$ to over $10^{-4} \cdot \mathrm{sec}^{-1}$ can be. . deduced with stresses in excess of $6 \times 10^{8}$ dynes $/ \mathrm{cm}^{2}$. If effective stress relaxation is to occur, viscoelastic strain rates at these stress levels should be orders of magnitude higher. Myshlyaev [4] and Graham [5] have studied single and polycrystalline silicon for tumpcratures in the range of $900^{\circ} \mathrm{C}$ to greater than $1300^{\circ} \mathrm{C}$. Considering the nature of RTR ribbon, possibly one should expect that material properties characteristic of polycrystaline silicon should be most appropriate although ribuon grain sizes are considerably larger. Graham finds that at $1380^{\circ} \mathrm{C}$ and. at strain rates of $8 \times 10^{-4} \mathrm{sec}^{-1}$, a stress level of $2.75 \times 10^{8} \mathrm{dynes} / \mathrm{cm}^{2}$ Is required. Grahams' data, while on polycrystalline material, are not inconsistent with that of Myshlyaev on single crystal samples. Myshlyaev arrives at the following expression for flow stresses in single crystal silicon for the studied temperature range $\left(900^{\circ} \mathrm{C}-1300^{\circ} \mathrm{C}\right)$ :

$\dot{\varepsilon}_{0}=10^{11} \mathrm{sec}^{-1}$

$$
\dot{\varepsilon}=\dot{\varepsilon}_{0} \exp \left[\frac{-\left(u_{0}-V_{0}\right)}{k T}\right]
$$

$U_{0}-5.6 \mathrm{eV}$

$V=2.7 \times 10^{-21} \mathrm{~cm}^{3}$

$\sigma=$ Shear stress in dynes $/ \mathrm{cm}^{2}$ 
$U_{0}$ is the activation energy required for dislocation movement while Vo can be thought of as the barrler reduction due to the presence of the stress field $\sigma$. Inverting this we find for the shear stress required to achieve a given strain rate $\dot{\varepsilon}$ is -

$$
\sigma_{Y}=\frac{k T}{V} \ln \frac{\dot{\varepsilon}}{\dot{\varepsilon}_{O}}+\frac{U_{O}}{V}
$$

Defining a yield stress as that stress required to achleve a strain rate of $10^{-5} \mathrm{sec}^{-1}$, we arrive at Table i. Also shown are normalized yleld stresses, $\hat{\sigma}_{y}=\sigma_{Y} / \alpha E$, where $\alpha$ is the thermal expansion coefficient and $E$. is Young's modulus. We have assumed $\alpha=4 \times 10^{6}, E=1.17 \times 10^{12}$ dynes $/ \mathrm{cm}^{2}$ or $\alpha E=4.68 \times 10^{6}$ dynes $/ \mathrm{cm}^{2}$. Most stresses in this paper will be normalized.

These data are reasonably consistent with that of Sylwestrowicz [6] who also has studied single crystal silicon properties for temperatures of $600^{\circ} \mathrm{C}-1345^{\circ} \mathrm{C}$. While the highest stress for the RTR growth example cited was $4.12 \times 10^{8}$ dynes $/ \mathrm{cm}^{2}$, most regions of stress are considerably. lower and consequently are below the yleld stress levels of Table 1. Patel et. al. [7] have also studied the flow stress behavior of silicon up to temperatures of $1000^{\circ} \mathrm{C}$, although their primary emphas is was towards germanium. Their results appear to be in considerable disagreement with the other investigators. Their findings at $1000^{\circ} \mathrm{C}$ are about one order of magnitude lower than those indicated in Table I. Furthermore, they present a curve for flow stress vs. temperature which would, if extrapolated, fall far below that of Table 1. The reason for this disagreement (although Patel et. al. claimed in their paper to be consistent with the measurements by Sylwestrowicz) is not clear, but the fact that measurements were limited to $1000^{\circ} \mathrm{C}$ leads one to accept the measurements by Graham, Sylwestrowicz and Myshlyaev as more appropriate. 
TABLE 1

SILICON YIELD STRESSES

$$
\left(\ddot{\varepsilon}=10^{-5} \mathrm{sec}, \alpha E-4.68 \times 10^{6}\right)
$$

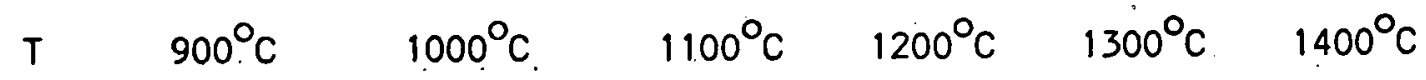

$\sigma_{Y} \quad 11.12 \times 10^{8} \quad 9.23 \times 10^{8} \quad 7.35 \times 10^{8} \quad 5.47 \times 19^{8} \quad 3.58 \times 10^{8} \quad 1.7 \times 10^{8}$

$\begin{array}{lllllll}\partial_{Y} & 267 & 197 & 157 & 116 & 76 & 36\end{array}$


These data then indicate that in a dynamic situation such. as RTR growth, slzeable in situ stresses may be sustained even at temperatures near that of the melt, and that a yield stress concept may be usefully employed. Correspondingly, the stresses implied by the elastic analysis of real thermal profiles and wide ribbons will be shown to be commensurate with these yield stresses, thus indicating the possibility of wide ribbon growth without excessive plastic strain if further improvements in thermal profile are made.

Ribbon buckling also attests to the presence of in situ stresses. Using classical results from the theory of elastic instability, it will be shown that buckling can be expected for wide sample growth unless improved thermal profiles are achieved.

\subsection{Theoretical}

Figure 2 indicates the geometry considered for the study. In cases of practical interest, the sample width (2C) and length are much greater than the sample thickness. In this case it can be assumed that thickness components of stress vanish in comparison to in-plane components, i.e. $\sigma_{z z}=\sigma_{x z}=\sigma_{y z}=0$. This is a condition of plane stress and the stresses may be found from solutions of the blharmonic equation [8]

$$
\nabla^{4} \phi=-\alpha E \nabla^{2} T
$$

or

$$
\partial_{x}^{4} \phi+2 \partial_{y}^{2} \phi+\partial_{y}^{4} \phi=-\alpha E\left(\partial_{x}^{2} T+\partial_{y}^{2} T\right)
$$

where

$$
\begin{aligned}
& \sigma_{X X}=\partial_{Y y}^{2} \phi \\
& \sigma_{y y}=\partial_{X X}^{2} \phi \\
& \sigma_{X y}=-\partial_{X Y}^{2} \phi
\end{aligned}
$$




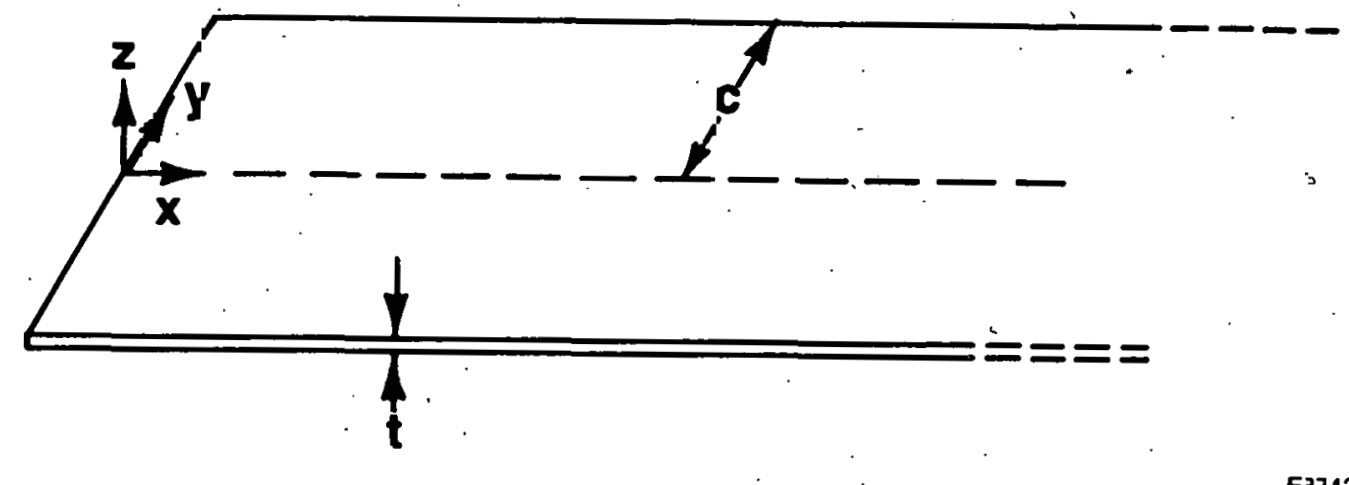

FIGURE 2: Sample geometry fer theoretical analysis. 
and $\alpha, E$ are the expansion coefficient and modulus of elasticity respectively. Boundary conditions on $\phi$ are required for a unique solution. At the melt $(x=0)$ and aty $= \pm C$ exist free boundaries, and on these boundarles it can be shown that the boundary conditions are

$$
\phi=\partial_{n} \phi=0
$$

where $\partial_{n}$ denotes the derivative normal to the surface. In this study, temperature variations are assumed to be entirely $x$ dependent (i.e. $\partial_{y}{ }^{\top}=\partial^{2}{ }_{y}^{T=0}$ ); consequently symmetry may be invoked about $y=0$. Boundary conditions along $y=0$ therefore are:

$$
\begin{aligned}
& \left.\partial_{y} \phi\right|_{y=0}=0 \\
& \phi(x, y)=\phi(x,-y)
\end{aligned}
$$

Finally, since a numerical solution is to be obtained, a boundary condition must be imposed at $: X=L$ where $L$ is the length of the ribbon segment. In this case it is assumed that the temperature distribution at $x=L$ is slowly varying with at most a parabolic dependence. "Slowly" is a situation specific term and in practice means that the curvature is hardly changing over distances comparable to the ribbon width. Under these conditions $\phi$ can be shown by analytic means [9] to be

$$
\phi(L, y)=-\frac{\alpha E}{24}\left(y^{2}-C^{2}\right)^{2} d^{2} x^{\top}
$$

\subsection{Numerical Solution}

Numerical solutions were obtained by the technique of finite differences using the Gauss-Seidel iterative relaxation technique. Because of the occurrence of thermal profiles exhibiting very large 
gradients and curvatures near $x=0$, the rectangular variable mesh system of Figure 3 was utilized. This allowed a much finer resolution near the molt where detall was necessary. For a rectangular mesh, the symbolic representation [10] for the finite difference weighting of nelghboring points for equation (3) is

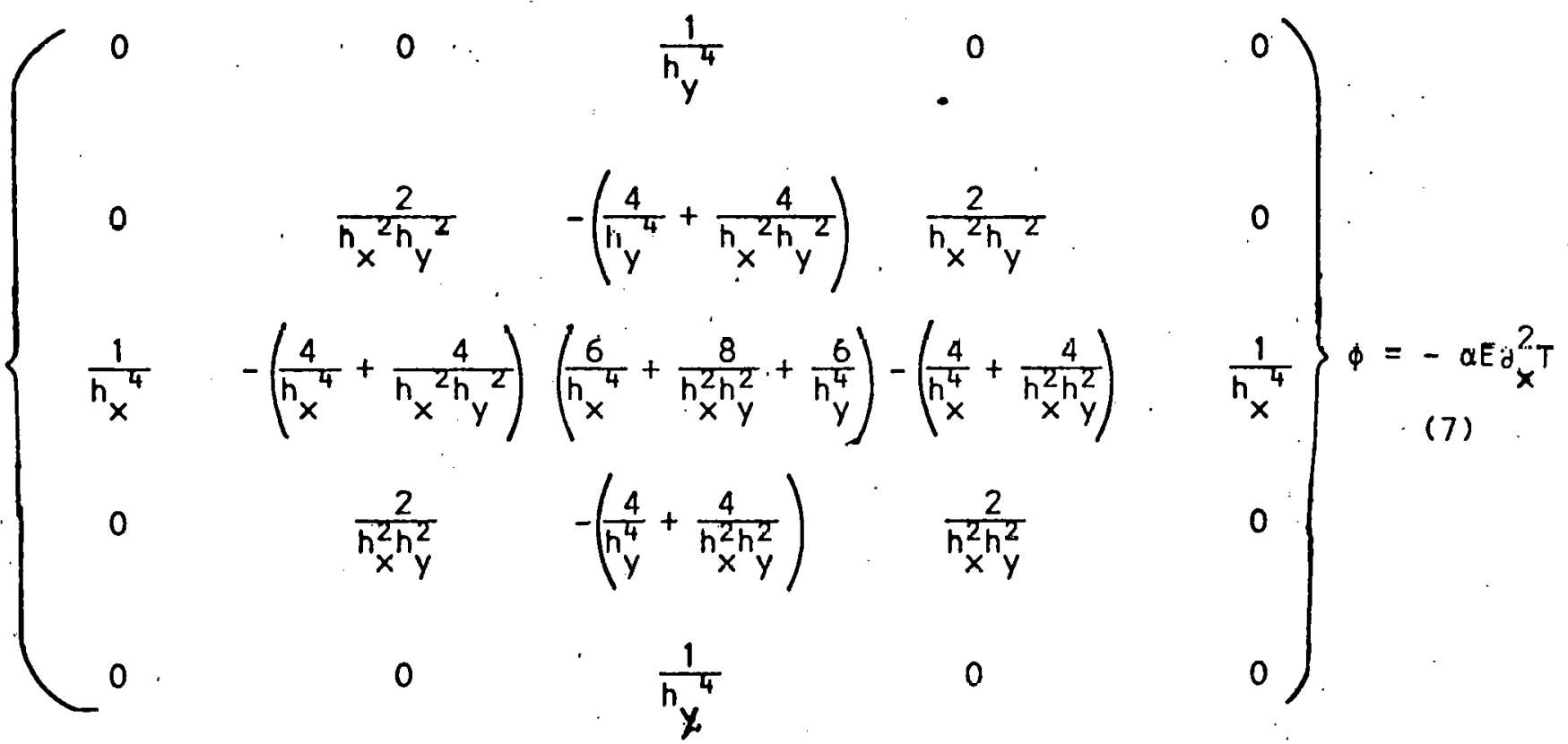

where $h_{x}$ and $h_{y}$ are the node separations in the $x$ and $y$ directions. During computation, an overrelaxation constant of 1.75 was utilized and iterations were continued usually until the stress potential at a key polnt changed by less than one part in $10^{6}$ per iteration. In some cases, notably very wide samples, somewhat less accuracy was accepted. Depending on the width of the sample, the coarse node separation was typically $1-2 \mathrm{~mm}$ while the fine resolution node separation was as small as $.25 \mathrm{~mm}$.

\subsection{Stress Distributions}

Because thero is no simple way to present complete stress distributions in detail (three components $\sigma_{x x}, \sigma_{y y}, \sigma_{x y}$ each a function of 


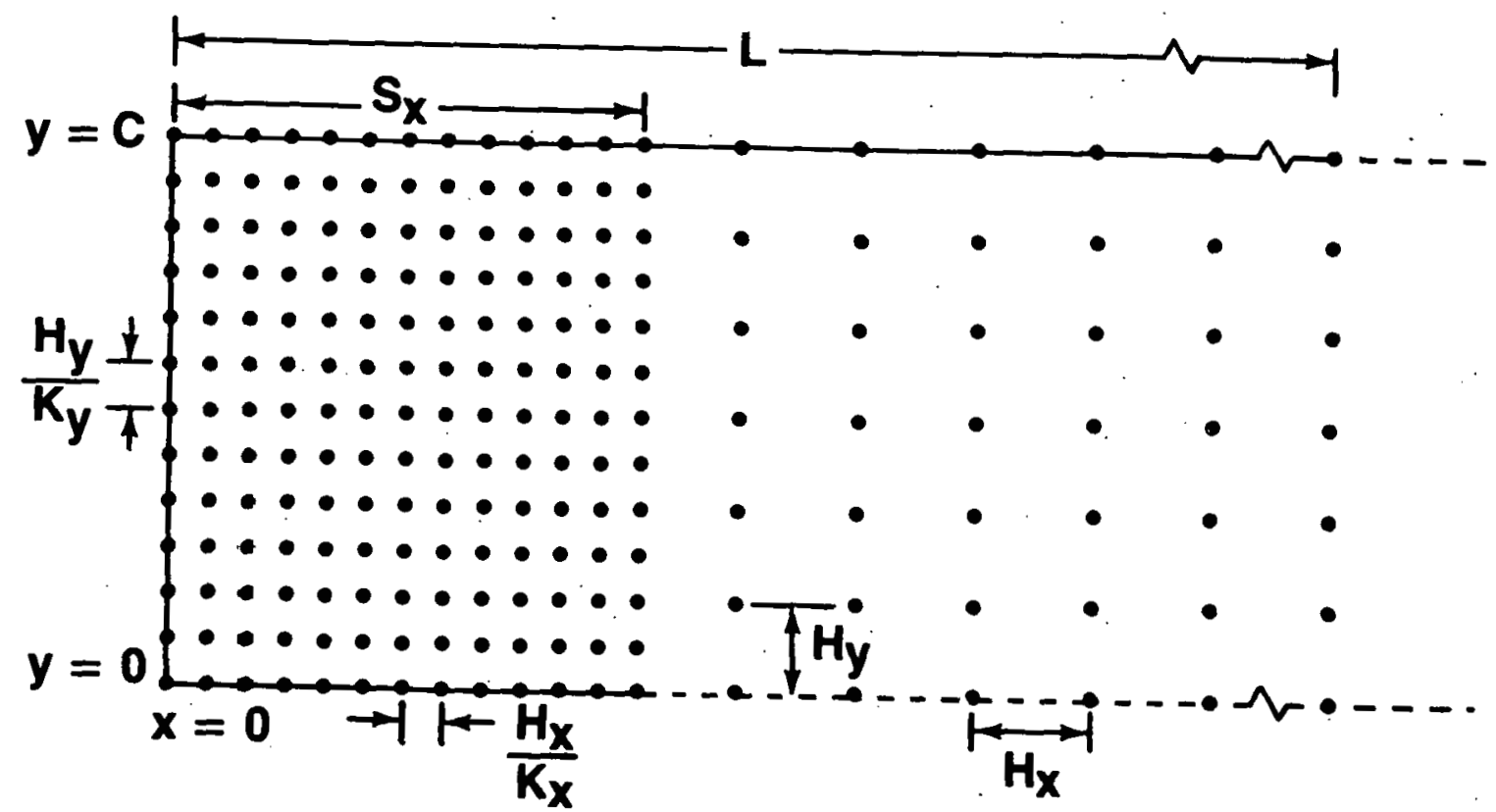

FIGURE 3: Mesh definition for numerical analysis. $K$ and $k_{y}$ are integers which increase the density of the mesh for the distance $5 x$ to give improved accuracy and where large variations in temperature occur. 
$x$ and $y$ ), only selected distributlons will be shown. First will be presented in some detail a very simple example which illustrates roughly the general behavior of all distributions. Then subsequent distributions will be considerably abbreviated.

\section{4 .1 Pure Parabolic}

As a first example, which illustrates many important aspects of the nature of ribbon stress distributions, and the effects of a free boundary (melt region), a pure parabolic temperature distribution is assumed, i.e.,

$$
d_{X}^{2} T=\text { constant }=400^{\circ} \mathrm{C} / \mathrm{cm}^{2}
$$

(See for exumple curve \#T5 of Figure 7 ).

While such a temperature distribution is nonphysical, (rapidly exceeding the melting point of silicon), it is simple to treat far away from the free end $(x=0)$ and in fact is given by equation (6). From equation (3) we find that for $x>>C$

$$
\begin{aligned}
& \theta_{x x}=-\frac{1}{6}\left(3 y^{2}-c\right) d_{x}^{2} T \\
& \theta_{y y}=\theta_{x y}=0
\end{aligned}
$$

For $c=1 \mathrm{~cm}, d_{x}^{2} T=400^{\circ} \mathrm{c} / \mathrm{cm}^{2}$, we have

$$
\theta_{x x}=-66.7\left(3 y^{2}-1\right)
$$

Thus, far from the end, only longitudinal stresses exist which vary quadrotically with y. Figures la - If illustrate the ralrulated stress distributions. Note the pronounced effect of the free edge. While 


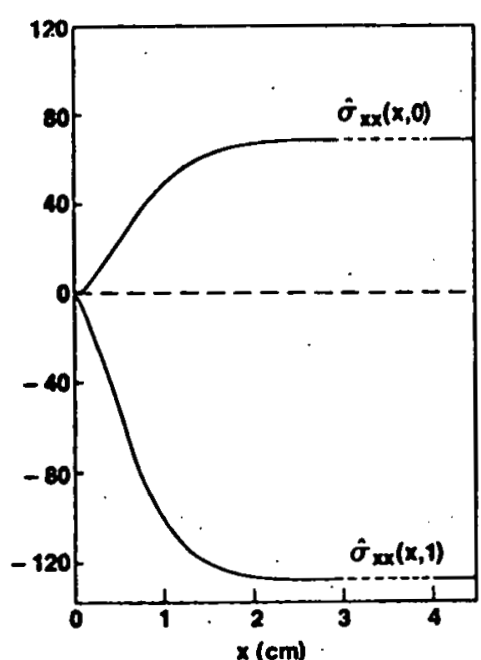

(b)

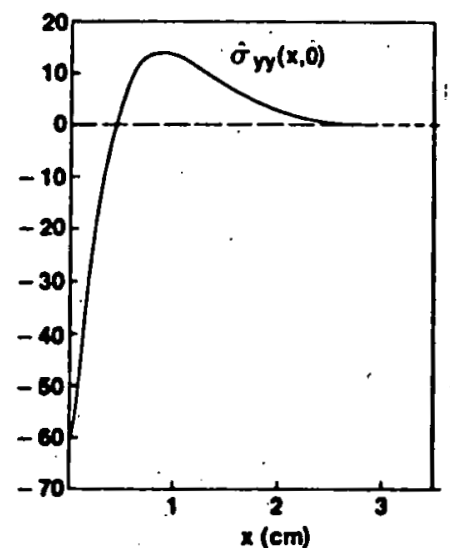

(c)

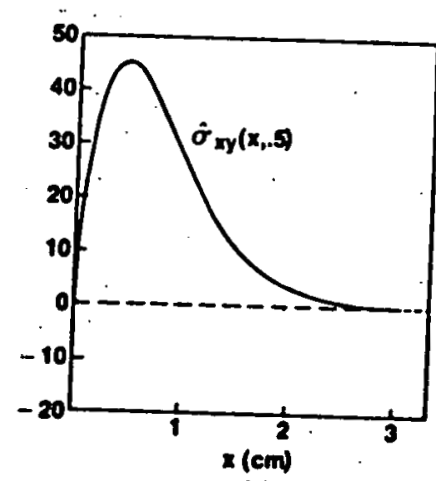

(c)

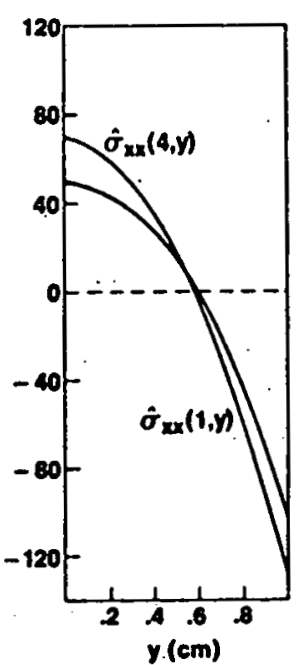

(b)

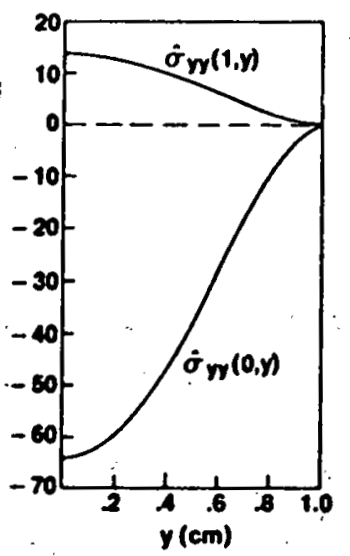

(d)

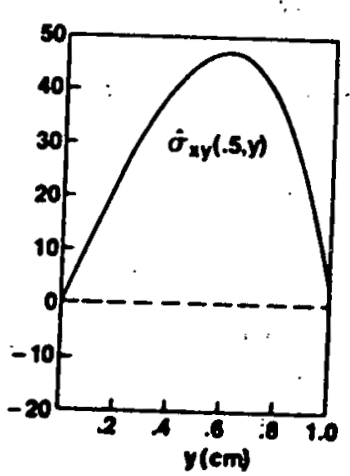

(1)

FIGUREE 4: Normalized stress* distributions for a $2 \mathrm{~cm}$ wide sample with the temperature profile T5 of Figure 7 .

* The stresses are all normalized to the dimensionless parameter. $\theta=\sigma / \alpha E$, where $\alpha$ is the thermal expansion coefficient and $E$ is Young's modulus. 
$\theta_{x x}$ is large and $\theta_{y y}=0$ for $x$ large, the reverse is true at $x=0$; there, $\theta_{x x}=0$ and $\theta_{y y}$ is large. In the region $0<x \leq 2$, shear stresses $\left(\theta_{x y}\right)$ temporarlly become large, and $\sigma_{y y}$ alternates in sign and damps to zero. Note the good agreement of the numerical solution with the analytical solution far from the edge.

This complex behavior has arisen, not because of a complex temperature distribution, but simply because of the presence of a free edge in a simple non-linear temperature distribution. The dominance of lateral and shear stresses in the vicinity of the melt is characteristic of ribbon stresses.

\subsubsection{Limited-Extent Parabolic}

Another simple example illustrates that a non-linearity acting over a short distance will lead to considerably lower stresses as compared to a non-linearity which acts over a length sufficlent to produce fully developed stresses. Figure 5 illustrates several linear-parabolic-linear temperature profiles, each with an equal curvature of $400^{\circ} \mathrm{c} / \mathrm{cm}^{2}$ in the central parabolic region, but with the parabolic profile extending over varlous "interaction" lengths. The center of the curved portion is placed $3 \mathrm{~cm}$ from the and of a $2 \mathrm{~cm}$ wide sample.

Figures $6 a$ and $6 b$ show computed stresses for the various cases. Also included is the pure parabolic stress distribution for comparison. Note that only for an interaction length of approximately the width of the ribbon do peak stresses approach that of the pure parabolic distribution while shorter interaction lengths give progressively lower stresses. 


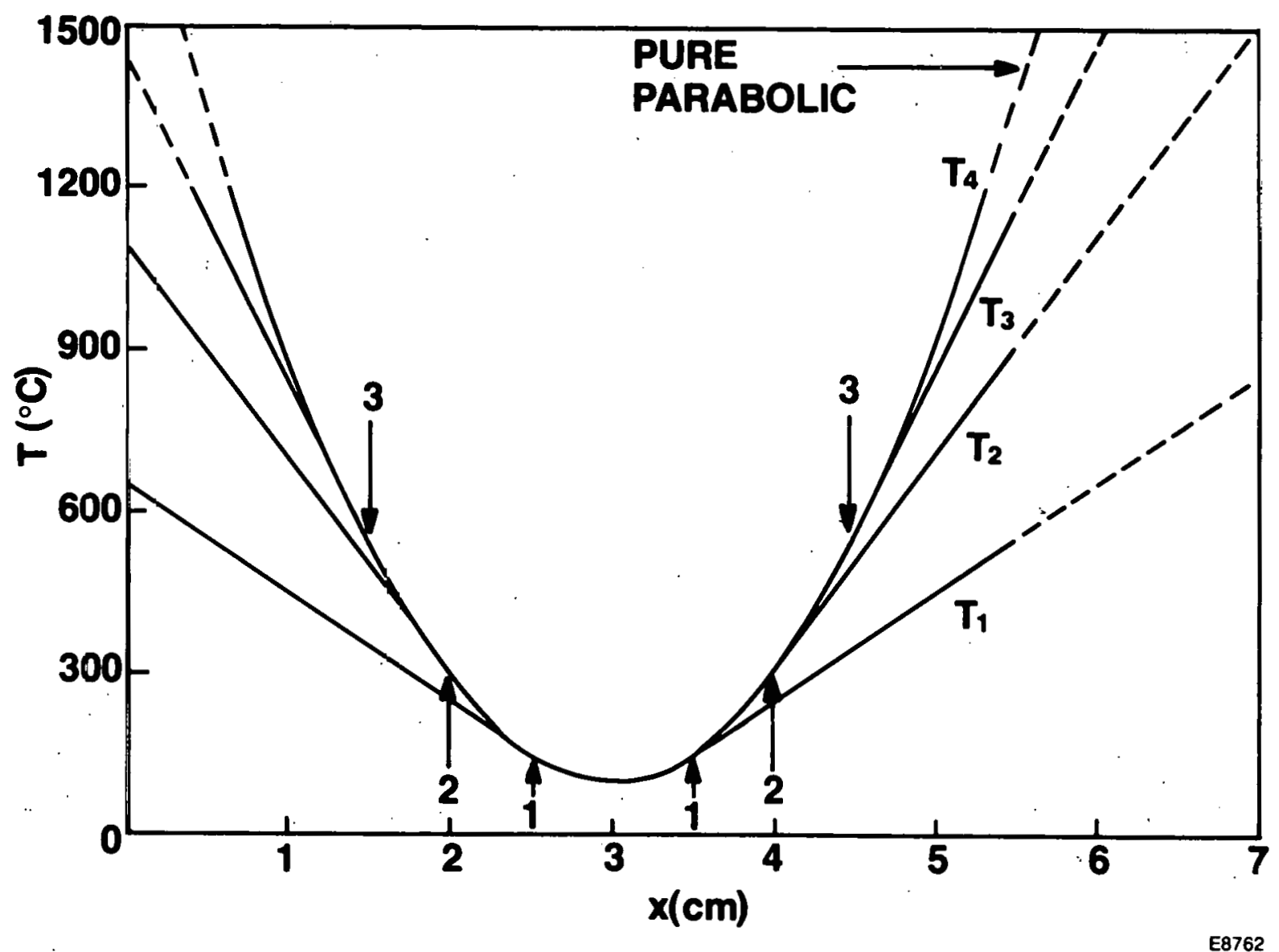

FIGURE 5: Linear-parabolic-l inear temperature profiles. The

parabolic-linear transitions are noted for each profile. 


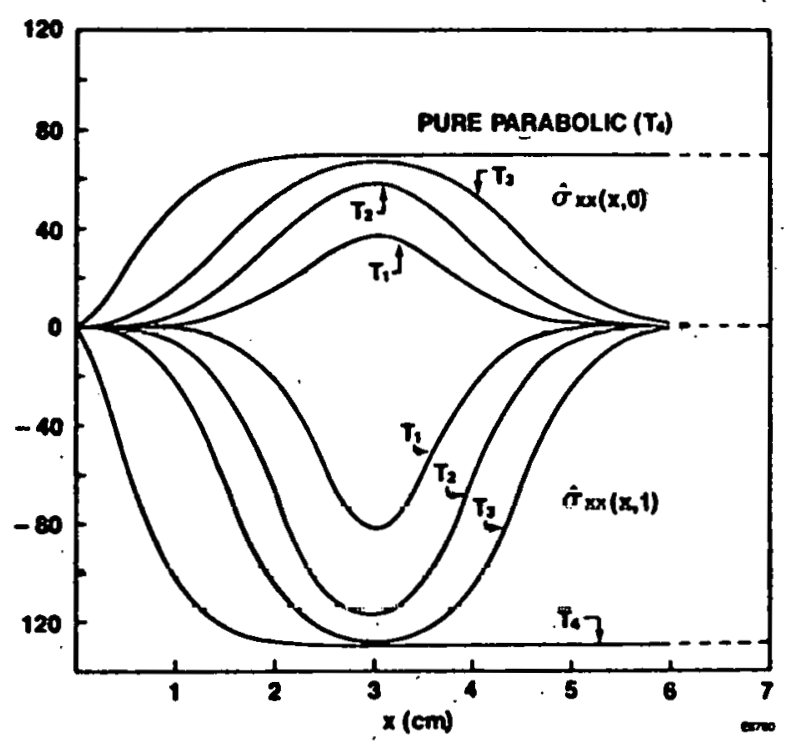

(A)

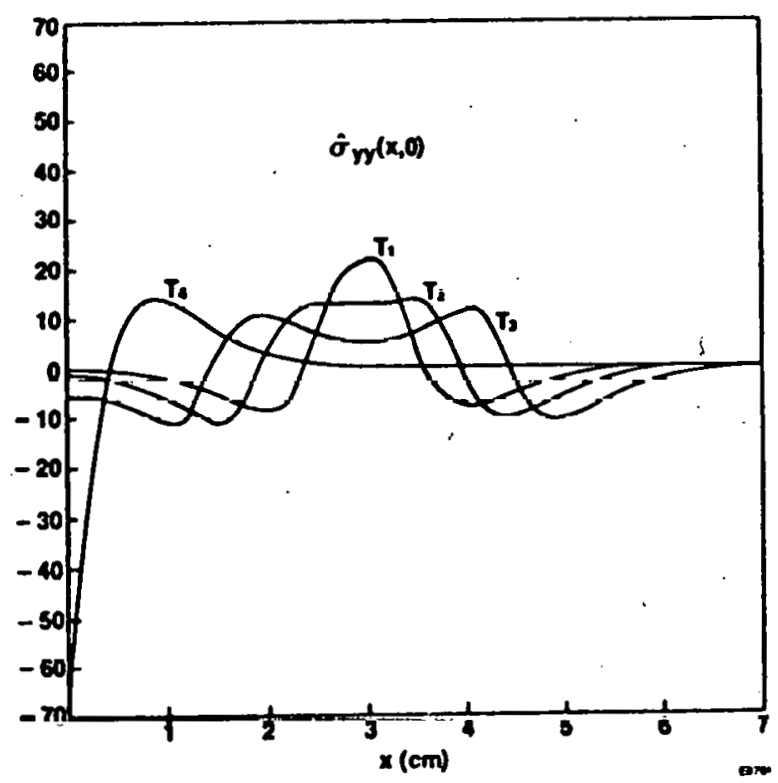

(B)

FIGURE 6: Stress ${ }^{*}$ distributions for a $2 \mathrm{~cm}$ wide sample with the various temperature profiles of Figure 5 .

* The stresses are all normalized to the dimensionless parameter $\theta=\sigma / \alpha E$, where $\alpha$ is the thermal expansion coefficient and $E$ is Young's modulus. 


\subsubsection{Free-End Proxlmlty Effects}

If a given thermal non-linearity is brought close to the free end, the nature of the stresses, and their magnitude, change dramatically. Figure 7 illustrates various linear-parabolic-linear temperature profiles of equivalent shape (interation length $=.5 \mathrm{~cm}=\mathrm{c} / 2, d_{x}^{2} T=800^{\circ} \mathrm{c} / \mathrm{cm}^{2}$ ) but acting at various distances from the free end. Figures $8 a$ and $8 b$ illustrate the resulting stresses. Note the damping of the longitudinal stresses but progressively increasing lateral stresses as the center of interaction approaches the end.

As a final example illustrating general trends, we consider the effects of sample width for the parabolic-linear temperature profile of Figure 7 when the parabolic region. is closest to the end (T5). Figures $9 a$ and $9 \mathrm{~b}$ indicate the stress distripution for sample widths $(2 \mathrm{C})$ of $i-8 \mathrm{~cm}$. While equation (9) would indicate that fully developed (longitudinal) stresses would vary as $\mathrm{C}^{2}$, a much reduced variation is observed in Figure 9. This is a result of a non-linearity both being of limited extenf and occurring quite near to the free end. Lateral stresses, however, do increase rapidly at first, but for the widest sample, a saturation is observed.

\subsubsection{Reallstlc Temperature Proflles}

The above considerations have indicated some important trends for ribbon shaped samples under the influence of various parabolic or piecewise-parabolic temperature profiles. Real temperature profiles are more complex. For example, figure 10 depicts the various contributions to a real temperature proflle. Shown are the calculated [i11]: temperature profile for a $.15 \mathrm{~mm}$ thick ribbon which is laser melted, an actual 


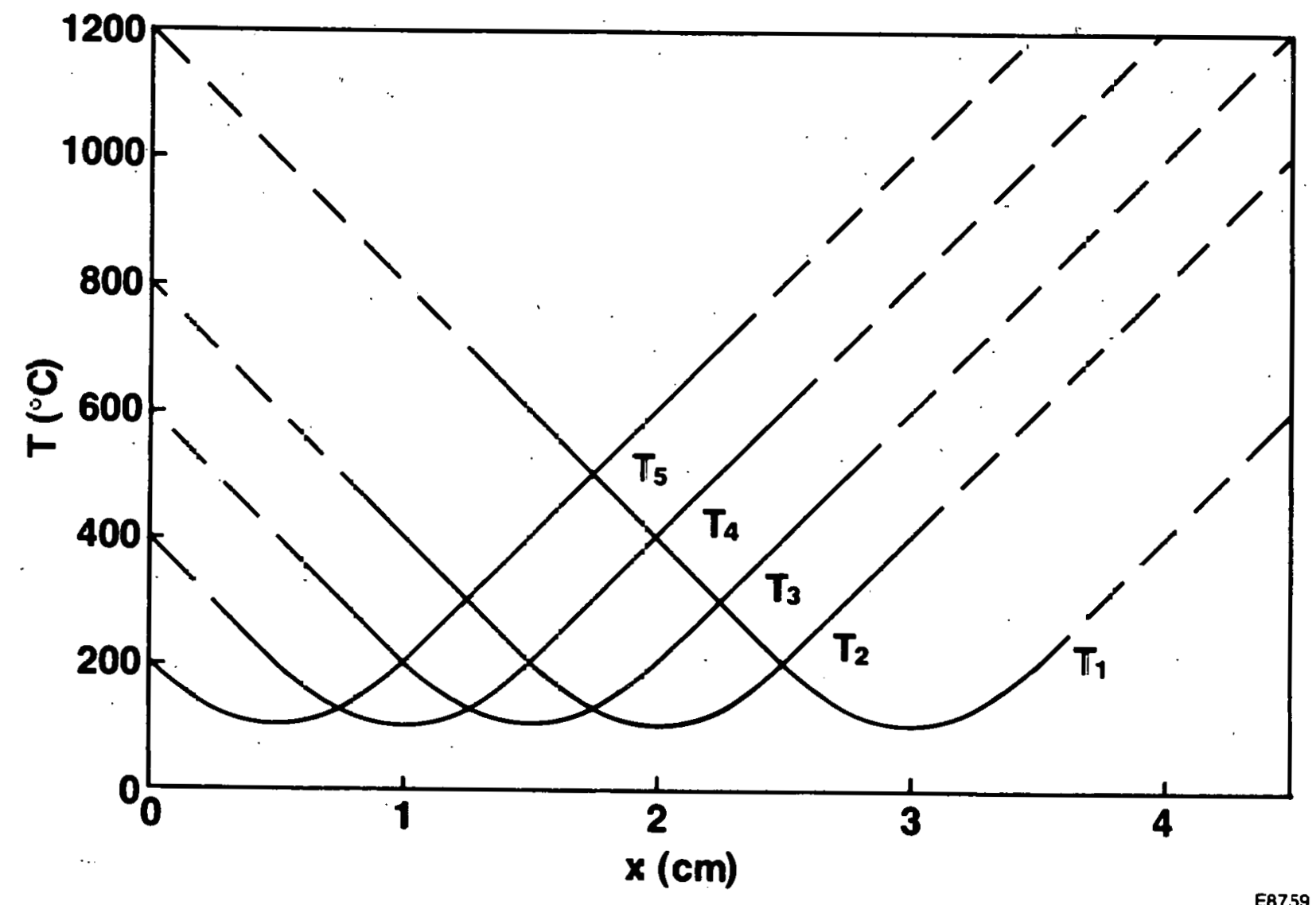

FIGJRE 7: Linear-parabolic-linear temperature profiles mposed at various locations with respect to a free end. The resulting. s-ress distritutions are shown in Figure 8. 


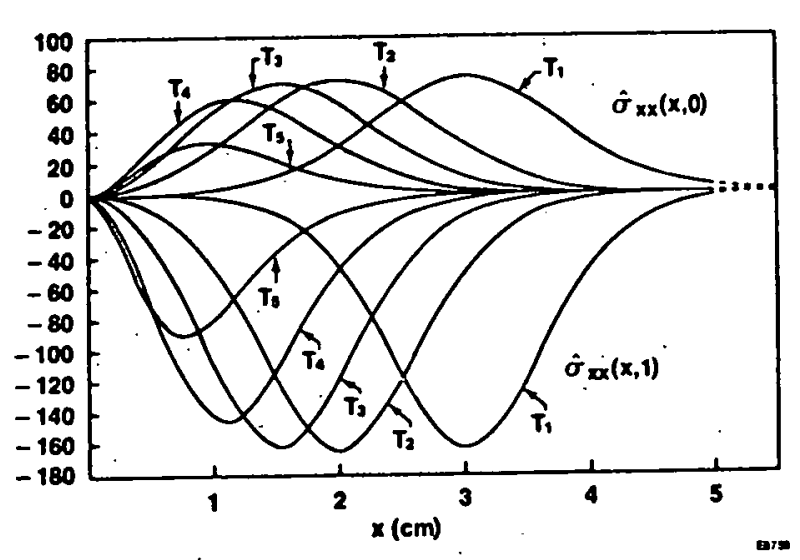

(A)

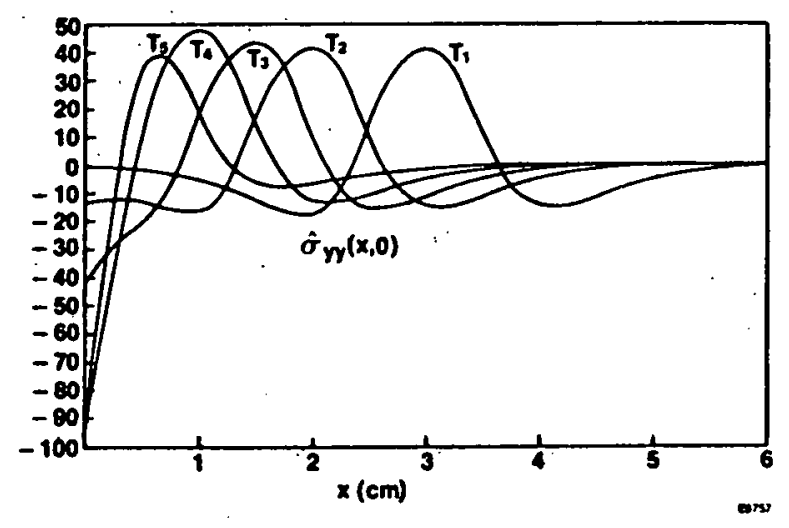

(B)

FIGURE 8: Stresš distributions resulting from a linear-parabolic-linear temperature profile imposed at various distances from the free end (melt) of a $2 \mathrm{~cm}$.wide ribbon.

* The stresses are all normalized to the dimensionless parameter $\theta=\sigma / a[$, where a is the lhermal expansion coefficient and $E$ is Young's modulus. 


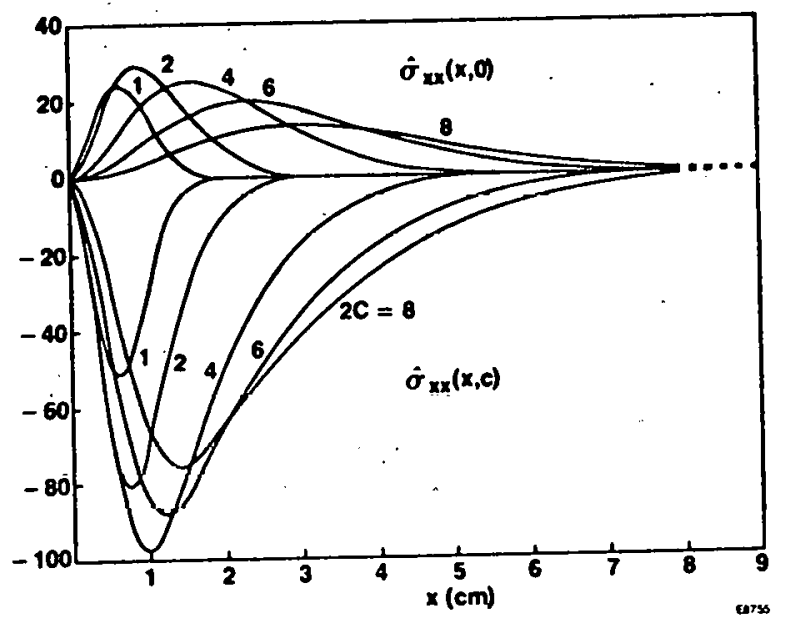

(A)

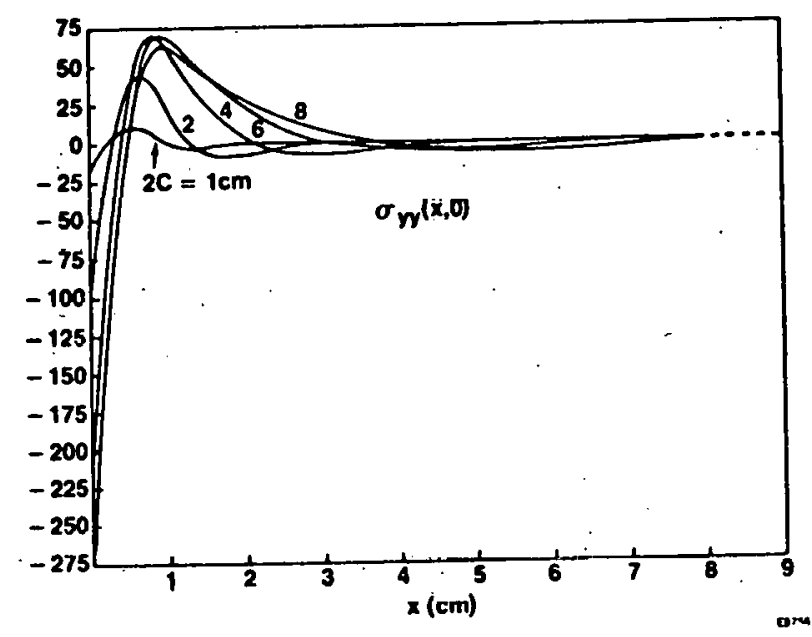

(B)

FIGURE 9: Width dependence of stresses* ${ }^{*}$ resulting from a paraboliclinear temperature profile (TS of Figure 7 ) imposed near the (ree end (melt) of a ribbion.

* The stresses are all normalized to the dimensionless parameter $\hat{\theta}=\sigma / \alpha E$, where $\alpha$ is the thermal expansion coefficient and $E$ is Young's modulus. 


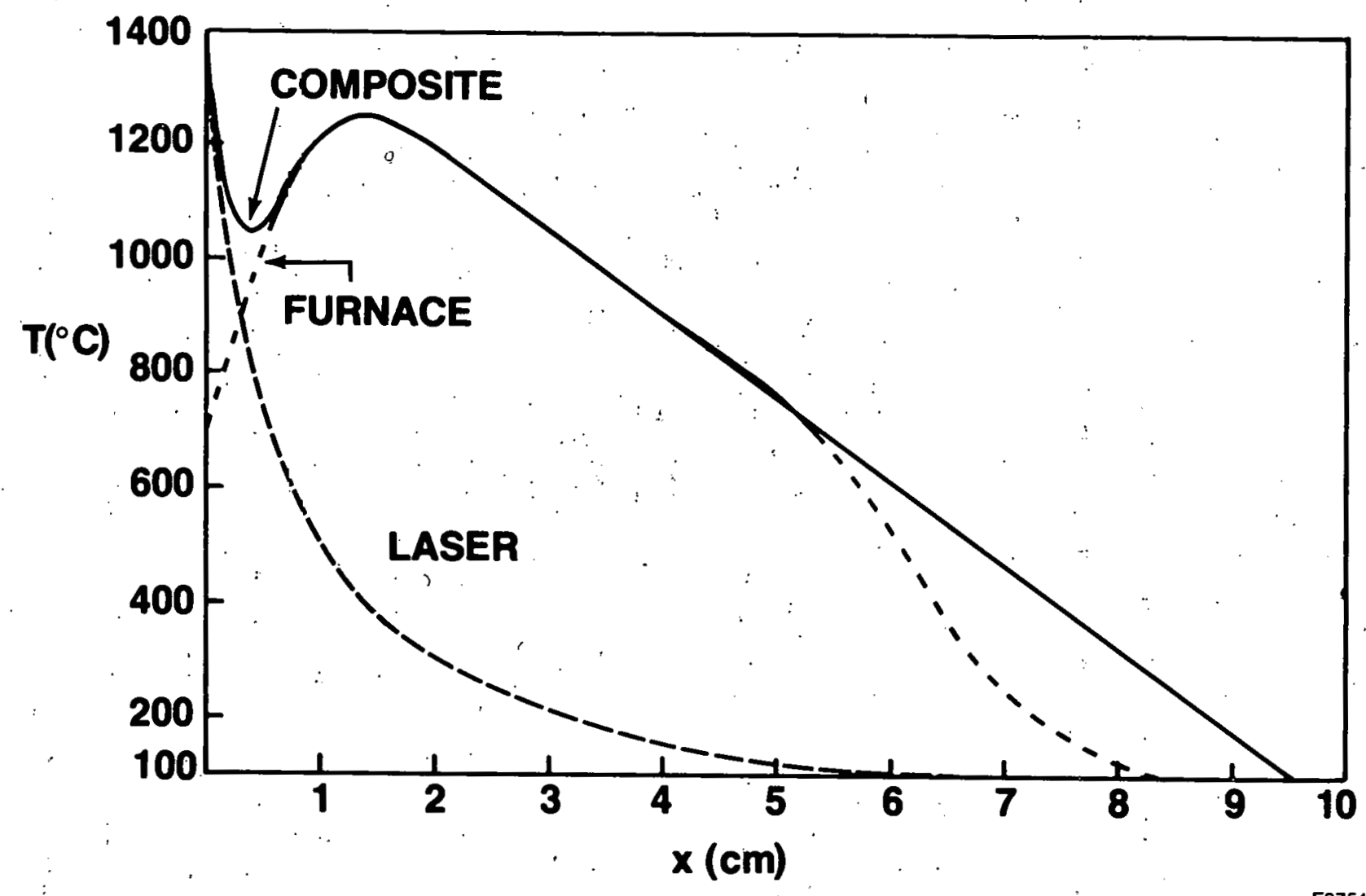

FIGURE 10: A "real" ribbon growth temperature profile is a composite of a laser-only (theoretical) and furnace-only (measured) profile. Also. shown is a-linearized version of the

composite profile which simplified the numerical analysis. 
(smoothed) furnace profile as measured by thermocouple profiling, and an intuitive, composite temperature profile which results when the laser and furnace are simultaneously used. Also shown, for simplification of. analysis, are linearized versions of the furnace and composite profiles.

It is interesting to calculate separately the stresses which would be caused by the laser-only profile, the linearized furnace-only profile and then the linearized composite profile.

The laser-only profile is typlcal of actual growth conditions during early RTR development. This profile is very steep and has very high, and variable, curvature near the melt. This particular profile has a curvature of $18,000^{\circ} \mathrm{C} / \mathrm{cm}^{2}$ at $x=0,1200^{\circ} \mathrm{C} / \mathrm{cm}^{2}$ at $x=.5 \mathrm{~cm}$ and dropping to $325^{\circ} \mathrm{c} / \mathrm{cm}^{2}$ at $x=1 \mathrm{~cm}$. Consequently, it might be expected that very large stresses would be encountered. Figures $11 \mathrm{a}$ and $11 \mathrm{~b}$ relate the computed stresses for each of the profiles for a sample width of $6 \mathrm{~cm}$. We see that qualitatively and quantitatively, the resulting stress distributions are quite different. Furthermore, the composite profile which approximates actual growth conditions, results in a stress distribution with surprising aspects. The composite profile appears to be more complex than either the furnace-only or laser-only profiles, yet the resulting stresses are considerably reduced in magnitude and extent. Even the lateral and shear stresses are markedly reduced as compared to the component profile stresses.

The new effect being observed here is the interaction of positive and negative curvature regions which tend to produce cancelling stresses. I In fact, superposition could be used, as the equations are llnear, but the composite profile is not simply the sum of the component temperature profiles.) 


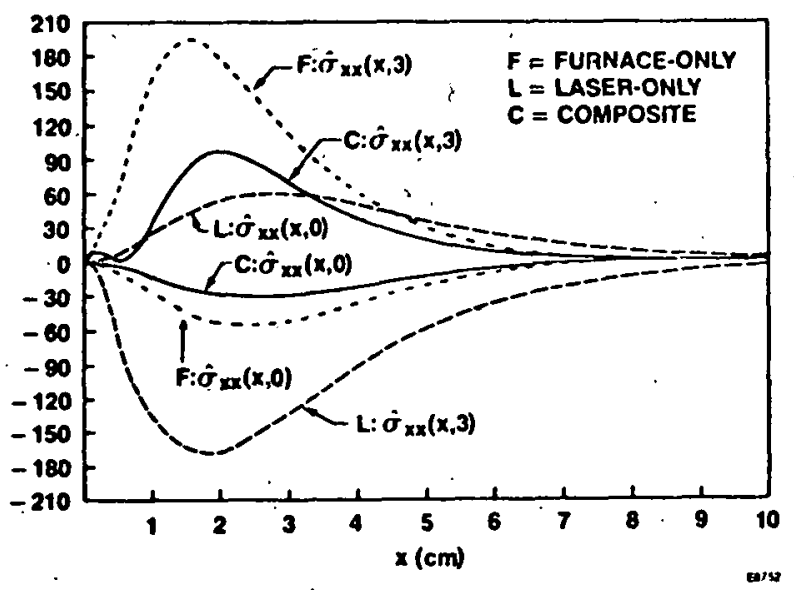

(A)

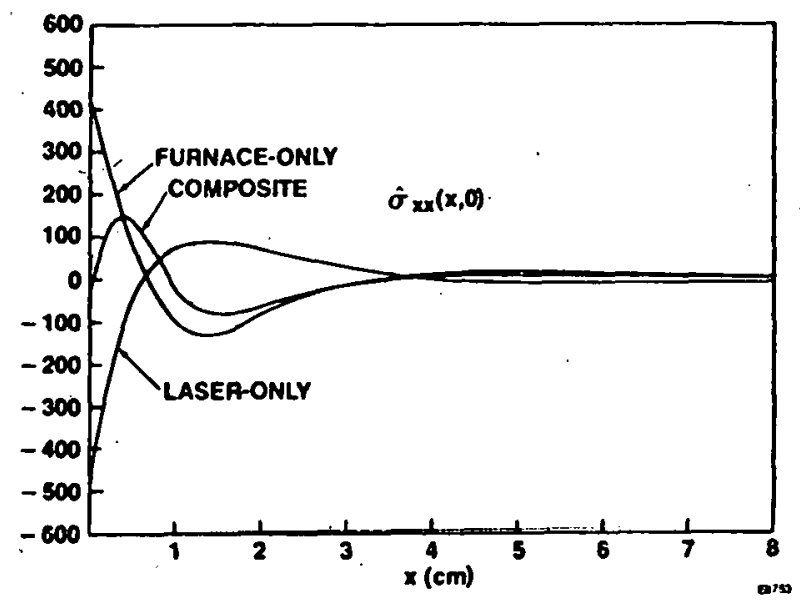

(B)

FIGURE 11: Stress $^{*}$ distributions in a $6 \mathrm{~cm}$ wide ribbon under the influence of (a) a laser-only profile, (b) a furnace-only profile and (c) a composite profile which might be typical of actual growth conditions.

* The stresses are all normalized to the dimensionless parameter $\theta=\sigma / \alpha E$, where $\alpha$ is the thermal expansion coefficient and $E$ is Young's modulus. 
Figures $12 \mathrm{a}$ and $12 \mathrm{~b}$ show the effects of width variation for the composite profile. These figures bring out another new aspect. The relatively simple symmetry between the central and edge longitudinal stresses no longer holds. As a function of width, the central stresses remain relatively simple while the edge stresses exhibit significant varlations with width; the narrower samples following more closely the expected behavior for the particular thermal profiles.

Finally, we note that virtually all stresses indicated are below the yield stresses of Table 1 (comparison must be made on a point-bypoint basis for stresses of Figure 12 and corresponding temperatures of Figure 10). The only exceptions are lateral stresses immediately adjacent to the melt. Of course, stress relief wlll occur throughout the growth region but these calculations indicate that the plastic strain rate will usually be too low to totally relieve the stresses.

\subsection{Thermal Profile Design}

In considering further improvements in the thermal profile, we are assuming that Insight gained from the study of an elastic model will be hel.pful because any stress reduction achieved on this basis, should lead to reduced dislocation generation, reduced buckling (see below) and generally improved crystal quality. From equation (3), and from the numerous examples cited previously, it would seem that the ideal profile would simply be a linear profile, i.e. $\partial_{x}^{2} T=0$. (More generally, if $\nabla^{2} T=0$ stresses would also vanish but considerations of this type lead us too far astray for the present discussion.). A strictly 


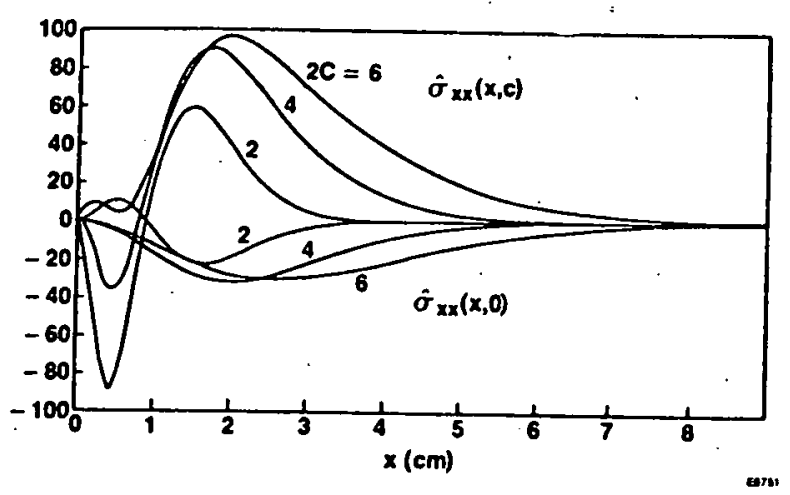

(A)

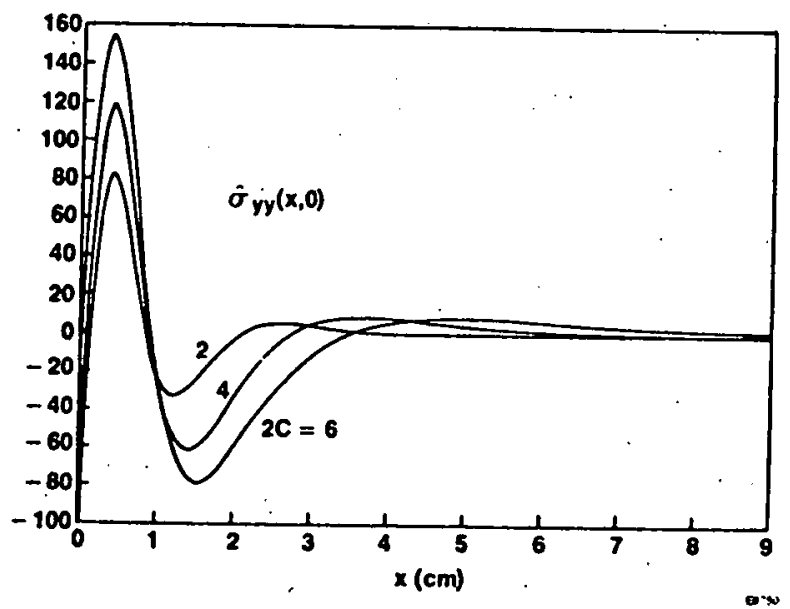

(B)

FIGURE 12: Width dependence of stresses ${ }^{*}$ in a ribbon with the composite temperature profile of Figure 10 .

* The stresses are all normalized to the dimensionless parameter $\delta=\sigma / \alpha E$, where $\alpha$ is the thermal expansion coefficient and $E$ is Young's modulus. 
linear profile is not possible, however, since at some point a minimum temperature will be reached which necessitates a region where $\partial_{x}^{2} T \neq 0$. For example, in order to achieve high growth velocities, a steep temperature profile is required at the melt which ensures latent heat of fusion extraction from the melt. Otherwise, the melt width becomes large and growth will become unstable [11]. For a growth velocity $v$, thermal conductivity $K$, and a latent heat of fusion per unit volume $H$, then the thermal gradiont at the mclt must be of the order of

$$
\left.a_{x} T\right|_{x=0}=-\frac{v H}{K}
$$

If, for example, $v=2.5 \mathrm{~cm} / \mathrm{min}=.0417 \mathrm{~cm} / \mathrm{sec}, K=.23 \mathrm{w} / \mathrm{cm} /{ }^{\circ} \mathrm{K}, H=4200 \mathrm{~J} / \mathrm{cm}^{3}$, then

$$
\left.\partial_{x}\right|_{x=0} \simeq-750^{\circ} \mathrm{C} / \mathrm{cm}
$$

Consequently, even if a linear profile of. this gradient were established, it could extend for a distance no longer than

$$
L=\frac{T_{M}}{\left|\partial_{x} T\right|} \simeq 2.25 \mathrm{~cm}
$$

since the temperature of the ribbon would then be absolute zero.

As an example of a realistic "ideal" profile, let us consider the profile of Figure 13. In this case we impose an initial gradient of $750^{\circ} \mathrm{C} / \mathrm{cm}$ which is held constant down to a temperature of $600^{\circ} \mathrm{C}$ and is then allowed to parabolically approach an ambient of $100^{\circ} \mathrm{C}$. Such a proflle might actually be achieved in the RTR process if scanned and modulated laser or electron beams were used to force the desired proflle. Figures $14 a$ and $14 b$ illustrate the resulting stresses for small ribbon widths. It is evident that for ribbon widths of current interest, e.g. $\gg 2 \mathrm{~cm} w / d e$, no benefit is achieved by this proflle and, in fact, stresses are worse than achieved with our present type of profile (Figures 12a, b). 


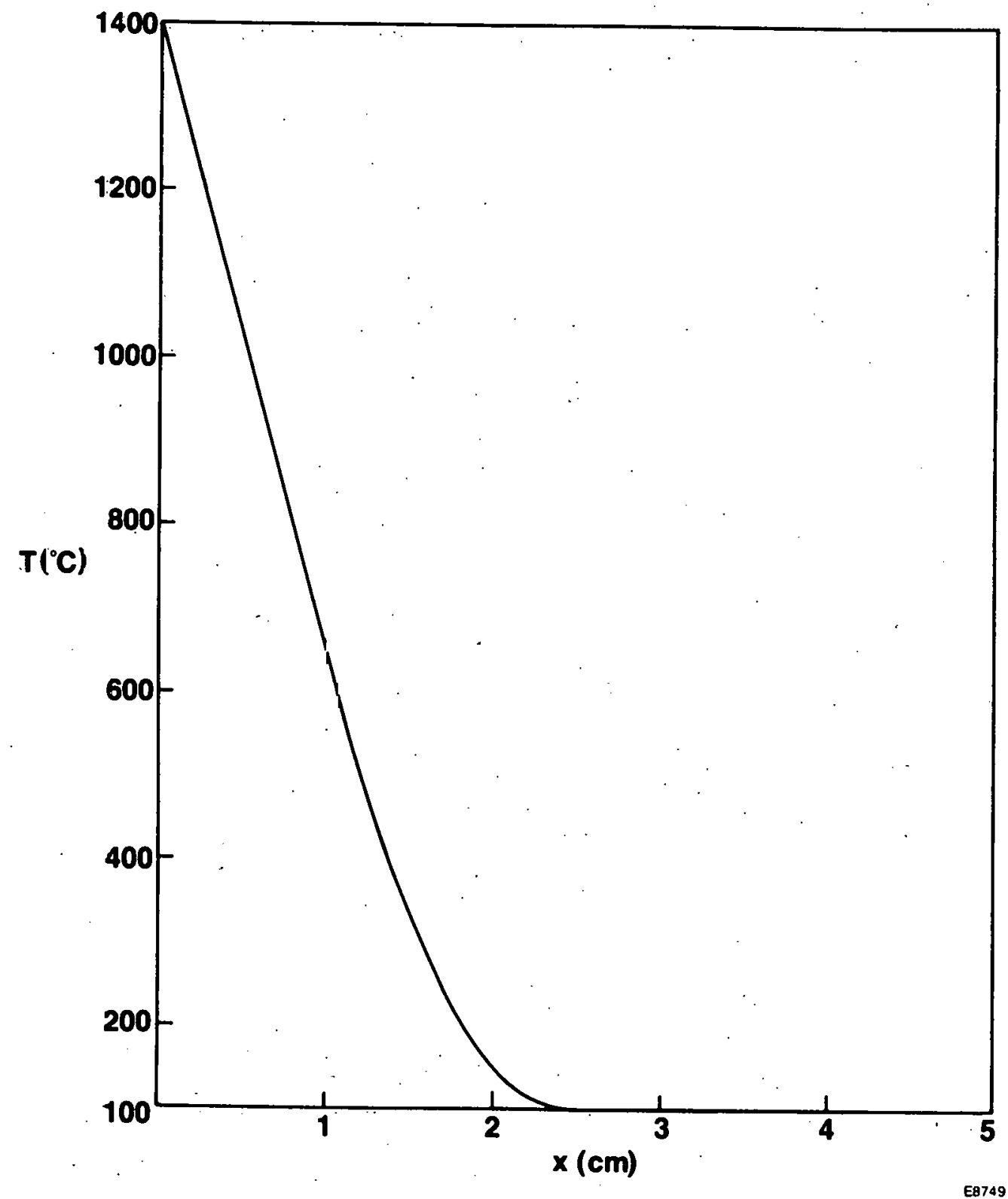

FIGURE 13: "Ideal" profile exhibiting a perfectly linear distribution from the melt down to a temperature of $600 \mathrm{C}$, then parabolically approaching an ambient temperature of $100^{\circ} \mathrm{C}$. 


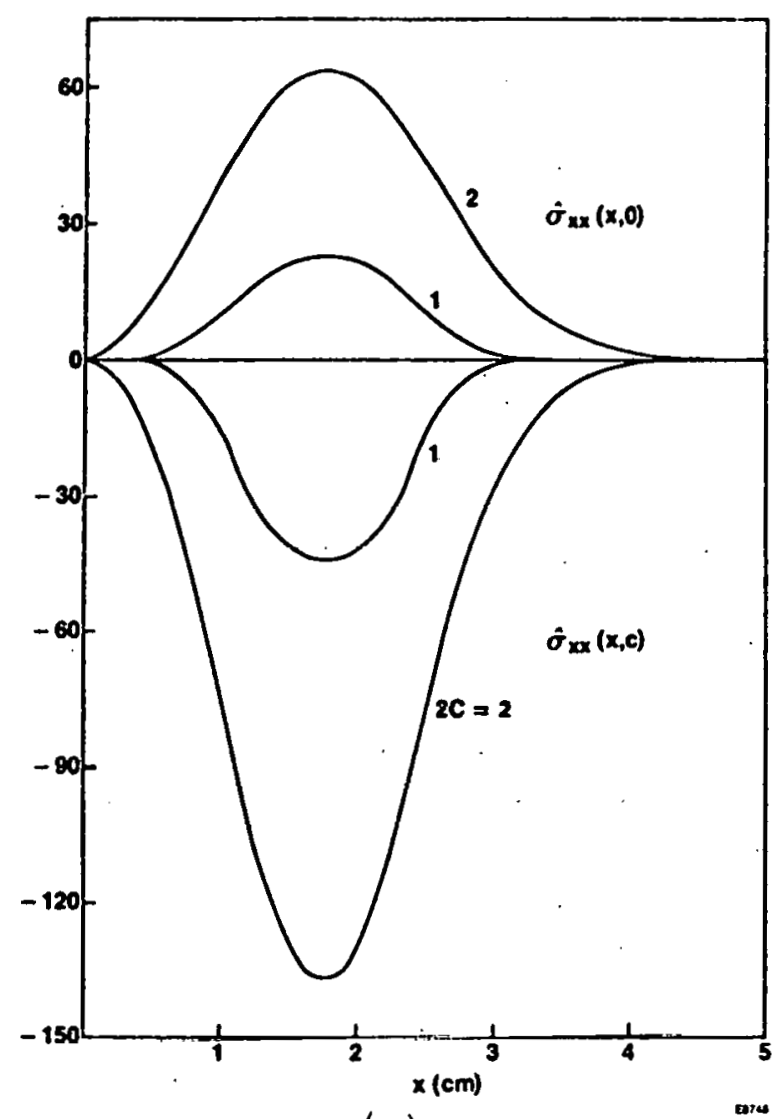

(A)

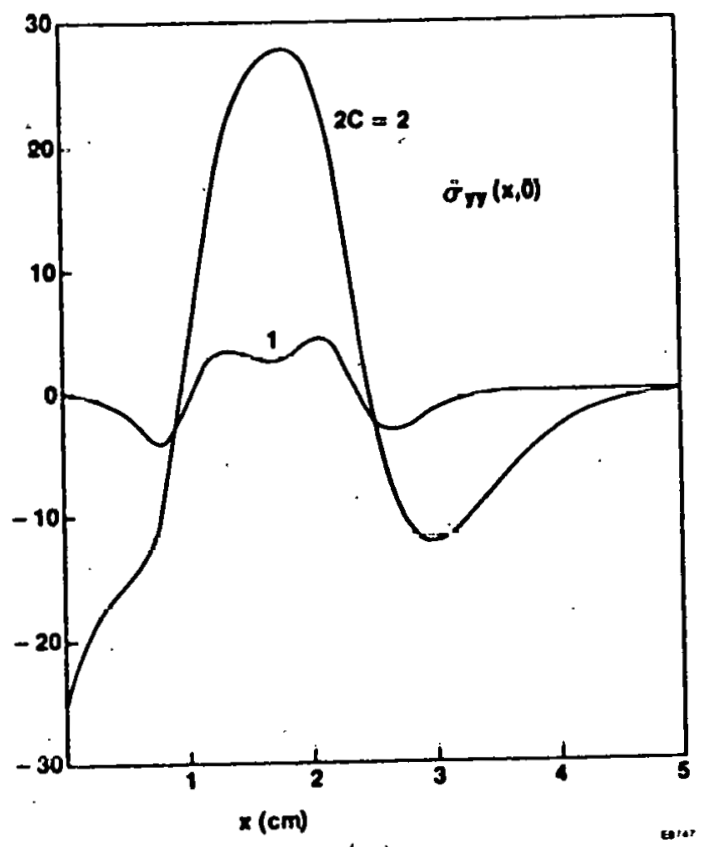

(B)

FIGURE 14: Stress"distributions arising from the "ideal" profile of Figure 13. For wide samples, very large stresses result.

* The stresses are all normalized to the dimensionless parameter $\hat{\sigma}=\sigma / \alpha E$, where $\alpha$ is the thermal expansion coefficient and $E$ is Young's modulus. 
We note, however, that for very narrow samples the stresses are very low for much of the region near the melt. For example, if. $2 C=1 \mathrm{~cm}$, stresses would be below the yield point for the entire ribbon since the region where stresses are largest occurs at lower temperatures where the yield stress is high. While growth of $1 \mathrm{~cm}$ wide ribbons seems counter to current development efforts, which are towards wider and wider ribbons, it is conceivable that large throughput could still be achieved with $1 \mathrm{~cm}$ wide ribbons. One method would be through multiple ribbon growth; forcexample $401 \mathrm{~cm}$ wide ribbons grown simultaneously at $2.5 \mathrm{~cm} / \mathrm{min}$ would lead to. $100 \mathrm{~cm}^{2} / \mathrm{min}$ growth. Such throughputs have been deemed as "economic" throughputs [12]. While the thought of growing 40 ribbons simultaneously is staggering, the RTR process is quite adaptable to multiple ribbon growth. Multiple growth of ribbons by the RTR process is relatively simple (and even routine) at present, and virtually no additional difficulty is encountered as opposed to ribbon processes requiring a die for shaping. of course; a much larger number of ribbons must now be processed and handling is increased. Such extreme methods would only be employed, however, if it can be shown that such an Ideal profile would actually result in significantly improved crystal quality and photovoltaic efficiency. The application of this technique is limited to roughly llie above parameters; $1 \mathrm{~cm}$ wide at $2.5 \mathrm{~cm} / \mathrm{min}$. Investigation of higher growth rates leads to unreasonably narrow samples while. wider samples demand slower growth rates which, assuming a constant throughput of $100 \mathrm{~cm}^{2} / \mathrm{min}$., meeris the overall processing width is excessive.

\subsubsection{Proflles for: Wide RIbbion Growth}

If wide ribbons are to be grown, the preceding discussion indicates that achleving low stresses near the melt with high growth rates is impossible. 
The former requires nearly linear, very low gradient profiles while the latter necessarily requires an initially very steep profile with subsequent large non-linearities. From the studies presented here, the only principle which can be seen to be effective for wide samples is to limit al. non-linearities to a region as close as possible to the melt, achieving a linear proflle as rapidly as possible. For example figüre 15. Indicates several profiles which restrict non-linearities closer to the melt until, for $T_{3}$, only a short positive curvature transition remains. $T_{1}$ and $T_{2}$ represent the range of profiles currently utilizod for RTR growth whlle $T_{3}$ represents a more idealized profile. Figures $16 a$ and b indicate stress distrlbutions for each of these profiles for a $6 \mathrm{~cm}$ wide ribbon. Profile $T_{2}$ produces much reduced stresses compared to those of $T_{1}$ whille those of $T_{3}$ become very small. Consequently, achievement of a thermal profile with a steep initial gradient to achieve high growth velocities but then immediately changing to a gentle linear slope can result in large throughput and very low stresses. Creating such a profile, however, would require a combination of active cooling adjacent to the melt and active heating in the Ilinear region -- a task requiring ingenious furnace and auxlliary heat transfer device design.

\section{1,6 Buckling of RTR Ribbons}

The pronounced buckling of RTR ribbons, as illustrated in figure 1, is must dramatic for wide ribbons grown at high velocity. It is also sensitive to the profile shape. For example, on $2.5 \mathrm{~cm}$ wide ribbons we can go from a condition of buckling to nearly flat growth simply by 


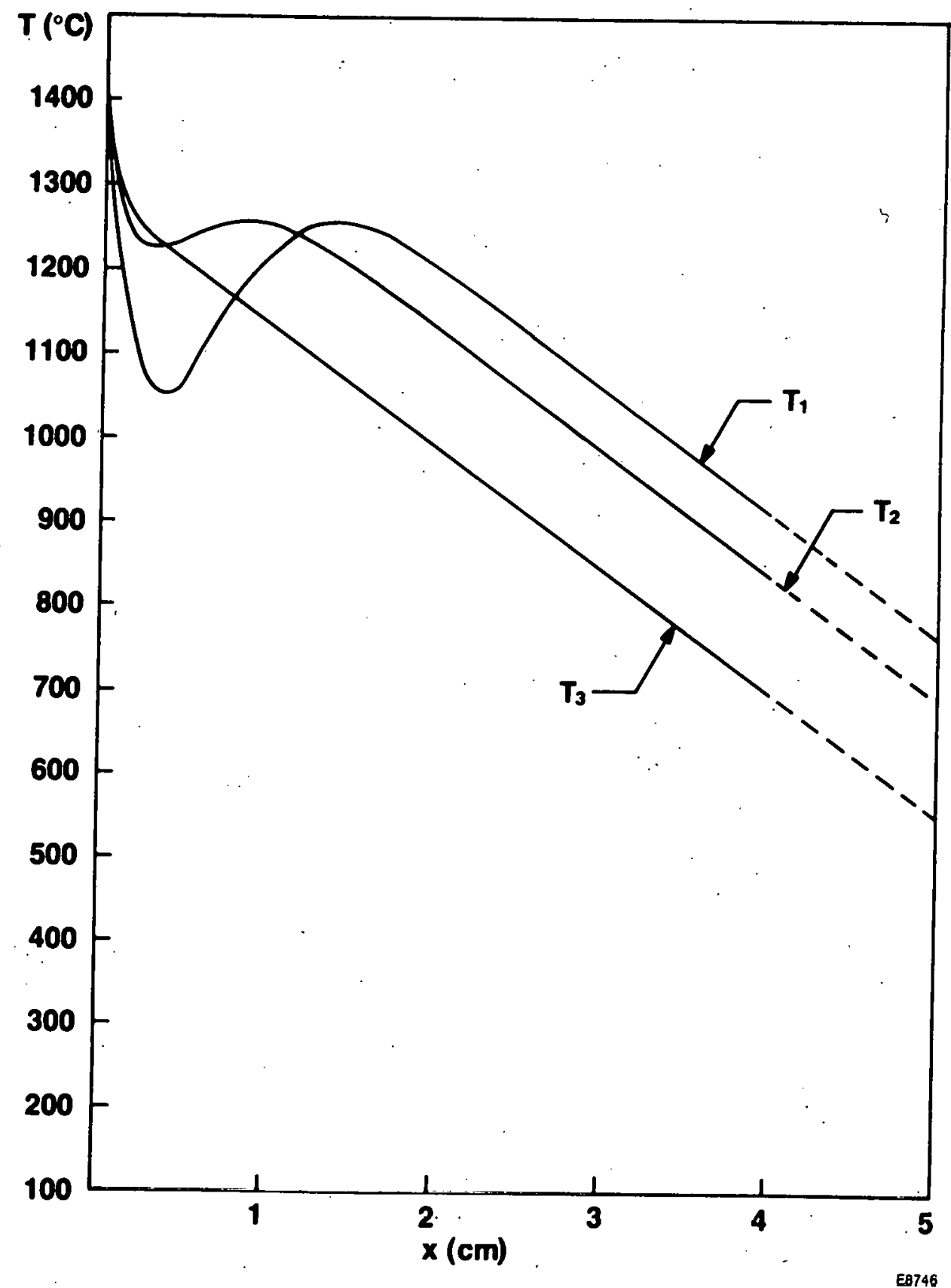

FIGURE 15: Profile improvements which can lead to improved, wide ribbon growth conditions. T2 represents conditions expected when the melt is moved closer to the postheater. T3 represents an ideal profile which achieves high growth velocity and low stresses (see Figure 16). 


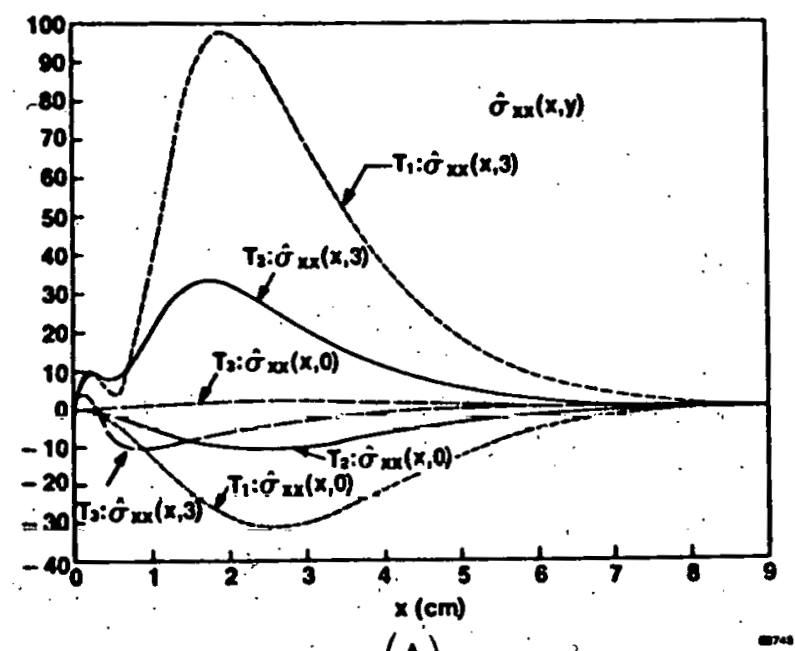

(A)

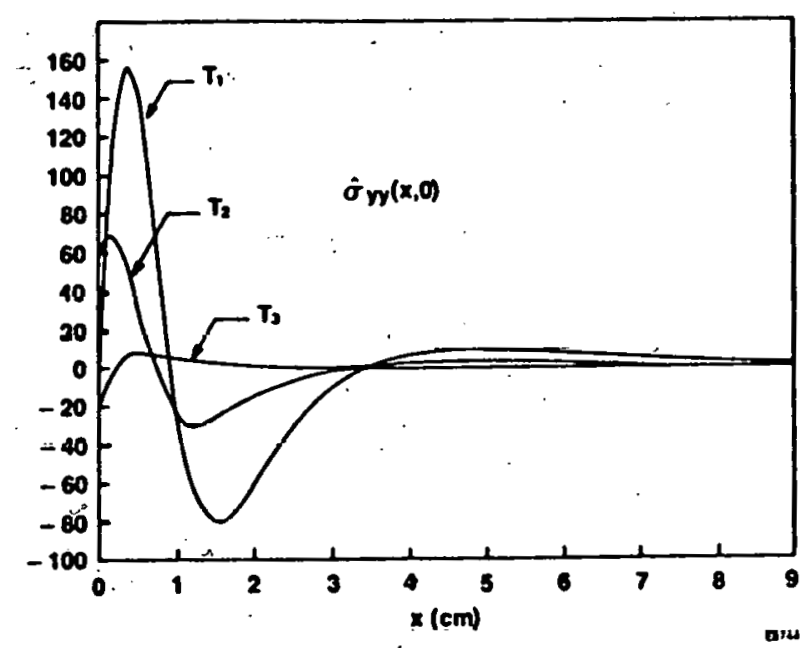

(B)

FIGURE 16: Stress ${ }^{*}$ distributions for the profiles of Figure 15.

* The stresses are all normalized to the dimensionless parameter $\partial=\sigma / \alpha E$, where $\alpha$ is the thermal expansion coefficient and $E$ is Young's modulus. 
moving the meit closer to the postheater. This is analogous to a change In thermal profile from that of $T_{1}$ to $T_{2}$ of Figure 15. Buckling has also been observed to cease once the dendritic growth regime [13] has been achieved. This occurs at the highest possible growth rate for a given thermal profile and is coincident with substantial alterations in thermal profile and melt configuration. These alterations are due to significant latent and sensible heat transport. The absence of buckling in this mode may be considered to result from one or both of two mechanisms. First, the alteration of thermal profile which occurs is such that stresses should be reduced. Second, the occurrence of dendritic formation leads to a "ribbed" structure which will tend to stiffen the ribbon against buckling [14].

\subsubsection{Buckling Mechanisms}

The buckling of ribbon under the action of in situ thermally induced stresses is readily understood. Figure 17 shows a flat element of ribbon under a uniform compressive stresses $\sigma$ and $\lambda \sigma$. If the compressive stresses are small, then the plate can absorb the energy of compression as elastic strain energy and any tendency to buckle will be opposed because the energy of bending (due to the internal stress) is larger than the virtual work that would be expended in bending the ribbon. Consequently, system energy would have to increase indicating system stability. On the other hand, at a critical level of compressive stress, the situation is reversed; under bending the total energy of the system can decrease and buckling may occur.

The treatment of elastic instabilities is highly devleoped, but only simple situations are conducive to exact analytic treatment. 


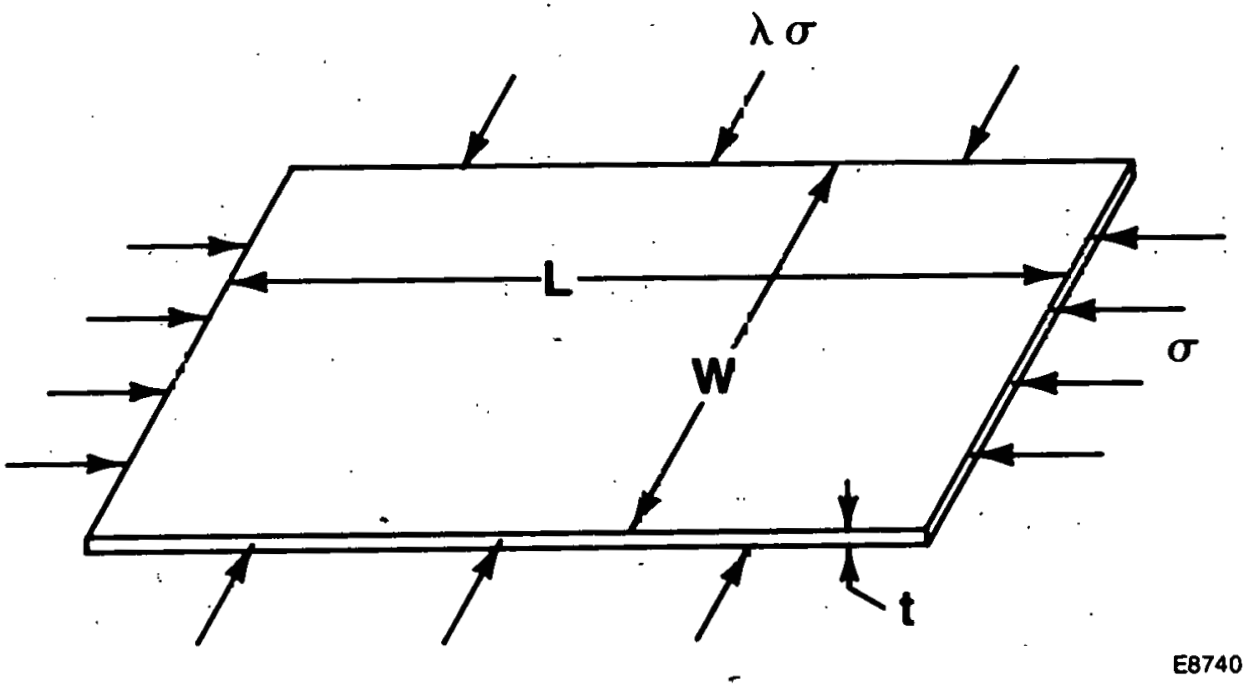

FIGURE 17: Thin plate acted on by un iform compressive stresses in the plane of the plate. For stresses exceeding a critical stress, $\sigma{ }^{\prime}$, the plate becomes unstable and buckling can occur. 
For example, analysis of a thin rectangular plate (Figure 17) of thickness $t$, with a compressive stress $\sigma$ acting along its length $\ell$, and a stress $\lambda \sigma$ acting along its width $W$, leads [15] to d critical compressive stress which can be written $\left(\right.$ for $\left.\frac{1}{2}<\lambda<2\right)$

$$
\sigma_{c r}=k \cdot \frac{E \pi^{2} t^{2}}{3\left(1-v^{2}\right) w^{2}} \equiv k \sigma_{0}
$$

where

$$
k \equiv \frac{\frac{1}{4}\left(1+\left(\frac{W}{l}\right)^{2}\right)^{2}}{\left(\frac{W}{l}\right)^{2}+\lambda}
$$

and $v$ is Poisson's ratio (assumed to be .25). (In this section, compressive stresses are usually of interest and are designated as positive, contrary to previous usage). The characteristic stress $\sigma_{0}$, may be evaluated if we assume typical conditions. Let us assume $E=1.17 \times 10^{12}$ dynes $/ \mathrm{cm}^{2}, t=.015 \mathrm{~cm}$, and $y=.25$ then

$$
\begin{aligned}
& \sigma_{0}=\frac{9.24 \times 10^{8}}{W^{2}} \text { dynes } / \mathrm{cm}^{2} \\
& \sigma_{0}=\frac{197}{W^{2}}
\end{aligned}
$$

and

or

$$
\begin{aligned}
& \sigma_{c r}=9.24 \times 10^{8} \frac{\mathrm{k}}{\mathrm{w}^{2}} \frac{\text { dynes }}{\mathrm{cm}^{2}} \\
& \theta_{c r}=197 \frac{\mathrm{k}}{\mathrm{w}^{2}}
\end{aligned}
$$

The restriction of the above relation to $\frac{1}{2}<\lambda<2$ is due to the nature of the complete instability analysis, which allows for numerous solutions, and a criterion of lowest energy must be determined. For the range given, a simple solution 
is possible and assumes simple $\frac{1}{2}$-wave distortion across the width and length. If $\lambda<\frac{1}{2}$, it is shown that

$$
\sigma_{\mathrm{Cr}}>(1-\lambda) \sigma_{0}
$$

Consequently, if $\lambda<0$ (i.e. a tensile stress is applied across the width) the tendency towards buckling is substantially inhibited.

Application of these results to ribbon growth can only be in a semi-quantitative manner. Consider, for example, the results of figures 120 and $12 \mathrm{~b}$ for 2,4 , and $6 \mathrm{~cm}$ wide ribbons. From these figures we note that compressive stresses arise primarily in the center of the ribbon and away from the melt zone. Large compressive stresses do occur for the 2 and $4 \mathrm{~cm}$ wide samples along the edges near the melt, while lateral stresses are all tensile in this region. Estimating the parameters to be utilized in evaluating equations (14) and (15) is acomplished by taking an "average" stress of $50 \%$ of peak and estimating the corresponding "width" and' "length" parameters with help from the "typical" curves of Figure 4. For example, for the $2 \mathrm{~cm}$. wide sample with compressive stresses on the outer edge, we estimate an average longitudinal stress of $\theta=40$, a length $\ell=.5 \mathrm{~cm}$ and a width $W=.2 \mathrm{~cm}$ (from Figure 4). While the lateral stresses appear high in Figure12b, at the edge region these stresses are considerably reduced and we take $\lambda=-.1$. Consequently we use equations (15) and (16) to estimate that

$$
\theta_{c r} \simeq \frac{1.1 \sigma_{0}}{(.2)^{2}}=5417
$$

Since $\delta_{\mathrm{Cr}} \gg \theta$ for this region, buckling is not likely to occur here. Applying the same estimating procedures to the same $2 \mathrm{~cm}$ wide sample 
for the compressive region of the central portion of the rlbbon we see that lateral stresses and longitudinal stresses are both compressive and act over larger regions. Here we estimate $\theta \simeq 11, \lambda=1.5, \ell=W=1 \mathrm{~cm}$. In this case we utilize equation (14) finding $k \simeq .4$ and $\theta_{\mathrm{cr}} \cong 79$. Again we see that the critical stresses appear to be much larger than are expected in a $2 \mathrm{~cm}$ wide sample and buckling should not occur.

As the sample width becomes larger, buckling becomes more likely. Going to the $6 \mathrm{~cm}$ wide sample of Figure 12 we see that compressive stresses occur only in the central portion of the ribbon and that both $\sigma_{x x}$ and $\sigma_{y y}$ are compressive. For this sample we estimate $\theta=15, \lambda \approx 2, \ell \approx 3 \mathrm{~cm}$, $W \simeq 3 \mathrm{~cm}$. This gives $\mathrm{k} \simeq .5$ and $\sigma_{\mathrm{cr}} \approx 11$. Consequently, under these conditions, buckling would be expected.

\section{6 .2 Discussion}

While the simple buckling instability considerations presented here indicate. critical stresses of roughly the same magnitude as predicted by the elastic analyses, application of these equations generally indicates that buckling is rather unlikely except for samples of considerable width. On the contrary, experiment indicates that ribbon buckling can occur even in $2 \mathrm{~cm}$ wide ribbons on occasion. Consequently, the threshold for buckling is of the correct order-of-magnitude, but fails to account for all observations. This discrepancy might be accounted for on the basis of a more exact buckling analysis which can more accurately account for the large peak stresses which occur. 


\subsection{Conclusion}

Elastic stress distributions described for a variety of ribbon thermal profiles indicate that ribbon stresses do not increase with sample width as rapidly as previously supposed. The calculated stress levels are also. shown to be usually below yield stresses computed on a strain rate basis, thus indicating that stresses are not rapidly relieved by plastic deformation. Two "ideal" proflles were described, one a profile which could theoretically result in no plastic flow but limited to narrow ribbon growth, and a second which is applicable to wide ribbon growth. Each profile requires deployment of ingenious techniques for its achievement. Finally, the classical theory of elastic instabllity has been applied to the resulting stress distributions in a semi-quantitative manner with partial success. Correct order-of-magnitude threshold stresses are obtained, but buckling of narrow ribbons cannot be accounted for. 


\subsection{CRYSTAL GROWTH}

A crystal growth rate of $\sim 55 \mathrm{~cm}^{2} / \mathrm{min}$ has been reached in two growth runs. The widths of the grown crystals were $7.3 \mathrm{~cm}$, the growth rate $7.6 \mathrm{~cm} / \mathrm{min}$. Due to the limited length of our samples, this growth rate was achieved for only $3-4 \mathrm{~cm}$. However, steady state growth was achieved, and the molten zone was stable. The sample was lightly dendritic, but the dendrites were not uniformly distributed over the width of the ribbon. Over one-half of the sample width, the dendrites grew in an ordered array, parallel to the growth direction, roughly $1 \mathrm{~mm}$ apart. Over the other half, however, the dendritic growth was disordered. Ordered dendritic growth can probably be established at somewhat higher growth rates, (and by improving the uniformity of the temperature profile across the ribbon) since the dendrites started growing only about 6.8 $\mathrm{cm} / \mathrm{min}$.

The grain size of RTR silicon ribbon grown from CVD material, was found to depend on the quality of the feedstock. The best ribbon was grown from feedstock that did not contain CVD growth spikes or nodules. The nodules are visible as black dots on the photograph of a CVD ribbon shown as Figure 18 . Figures 19 a, b are Wright-etched samples of ribbons grown from feedstock containing growth spikes (19a) and feedstock which did not contain growth spikes (19b). The growth spikes/nodules were essentially el iminated by increasing the deposition rate of the CVD ribbon, which produced a finer-grained ribbon.

\subsection{CONTROLLED DENDRITIC GROWTH}

By controlling the temperature gradient in the molten zone and through the solid-liquid interface, RTR silicon can be grown in a dendritic regime. The dendrites grow ahead of the normal solid-liquid interface and therefore can determine the microstructure of the growing ribbon. The number and size of the dendrites, as well as their distribution, are controlled by the temperature profile across the width of the ribbon 


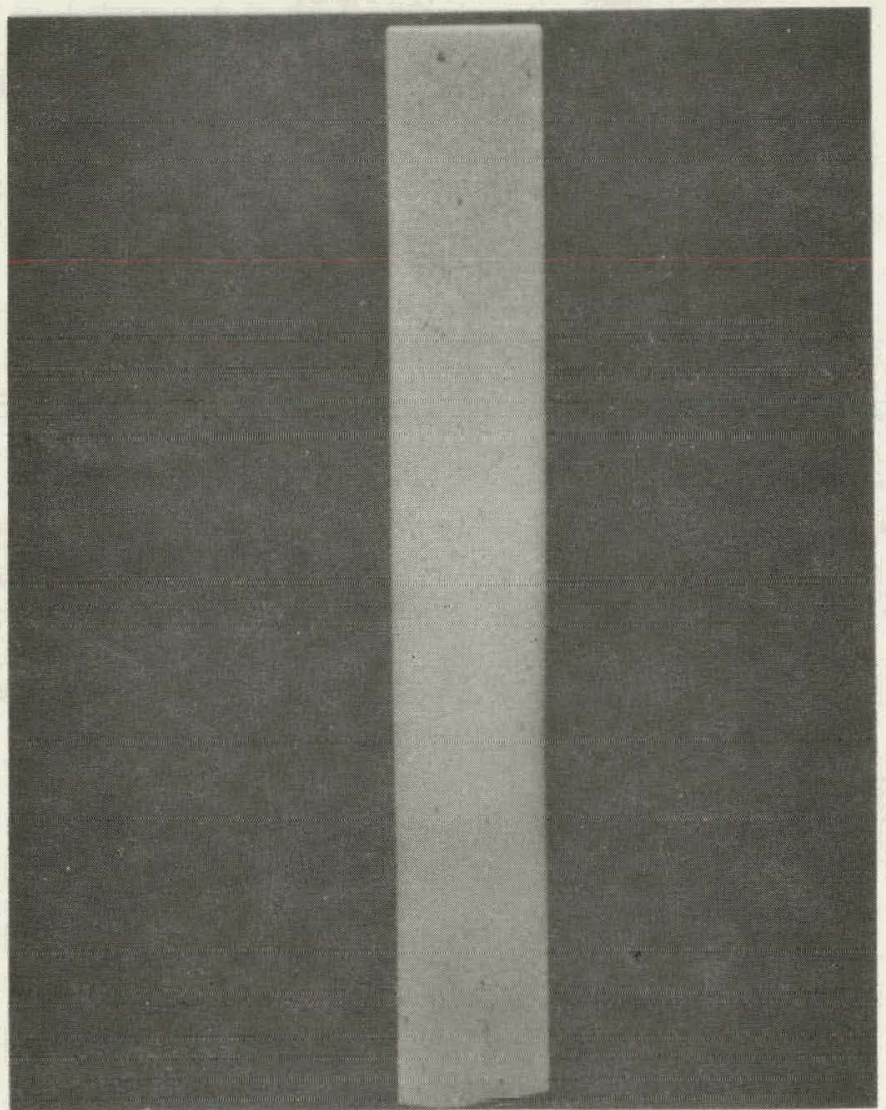

FIGURE 18: CVD RIBBON: THE BLACK DOTS ARE THE NODULES CONTAINING THE GROWTH SPIKES REFERRED TO IN THE TEXT. 


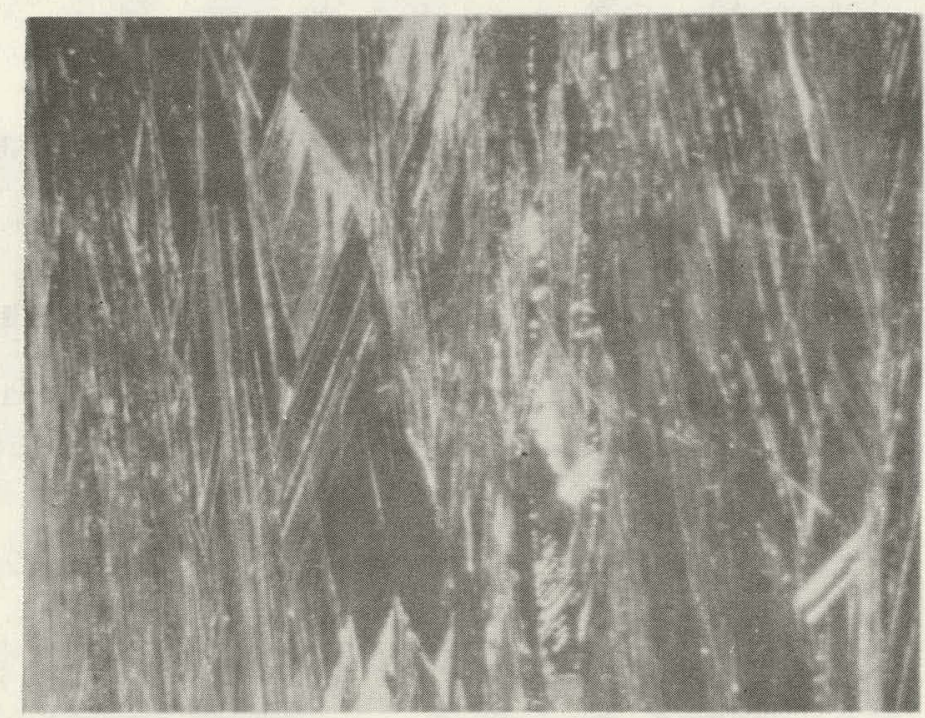

FIGURE 19a: RTR SAMPLE GROWN FROM FEEDSTOCK CONTAINING GROWTH SPIKES.

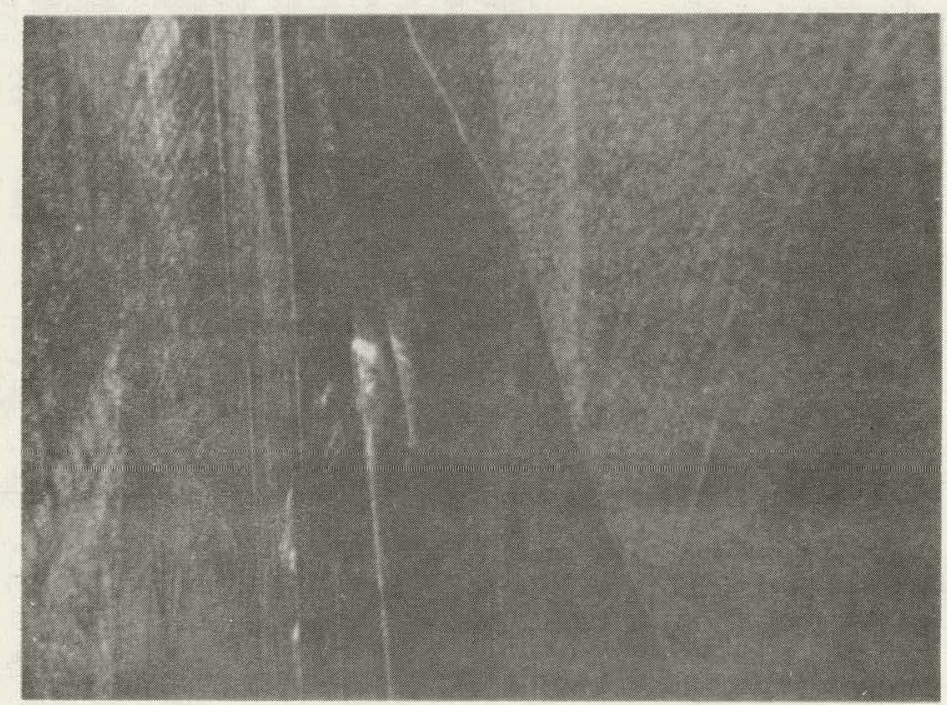

FIGURE 19b: RTR SAMPLE GROWN FROM FEEDSTOCK WHICH DID NOT CONTAII GROWTH SPIKES. 
and by the shape of the solid-liquid interface. If no attempt is made to control these parameters the dendrites will grow in a random fashion. This random growth can lead to an increased incidence of high-angle grain boundaries. Random growth can also lead to problems simply because it would result in a wide variation in ribbon topography and, therefore, in ribbon qual ity. Figures 20 and 21 are examples of the surface topography obtained with controlled and random dendritic growth, respectively.

Growth of dendrites can be controlled by imposing a temperature variation across the width of the molten zone. Figure 22 is an example of such a temperature variation, designed to produce a uniform dendrite distribution. The molten zone across the width of the ribbon is sufficiently supercooled to allow dendrite propagation. However, dendrite nucleation is only possible at a single point. Since the solid-liquid interface is curved, the dendrites grow at a small angle to the growth direction. As the ribbon growth progresses, the dendrite freezing point moves across the molten zone (See Figure 23). A second dendrite can then start at the same nucleation point. Eventually, the entire width of the ribbon would be covered with a uniform array of parallel dendrites.

Parallel dendritic ribbon also shows an improved microstructure. Figures 24 - 26 were taken from a section containing three parallel dendrites. After polishing, the section was etched for 3 minutes in Wright-etch, to delineate its defect structure. Two types of area can be distinguished. Within the dendrites (Figure 24) the silicon contains a fairly low density of twin planes/stacking faults as the only type of defect. The narrow areas in between dendrites contains two grain boundaries (Figure 25), and a high density of dislocations, as well as more twin planes/stacking faults. Note that the great etching depth at the grain boundary indicates a high energy defect; photons absorbed near the grain boundary would not contribute 


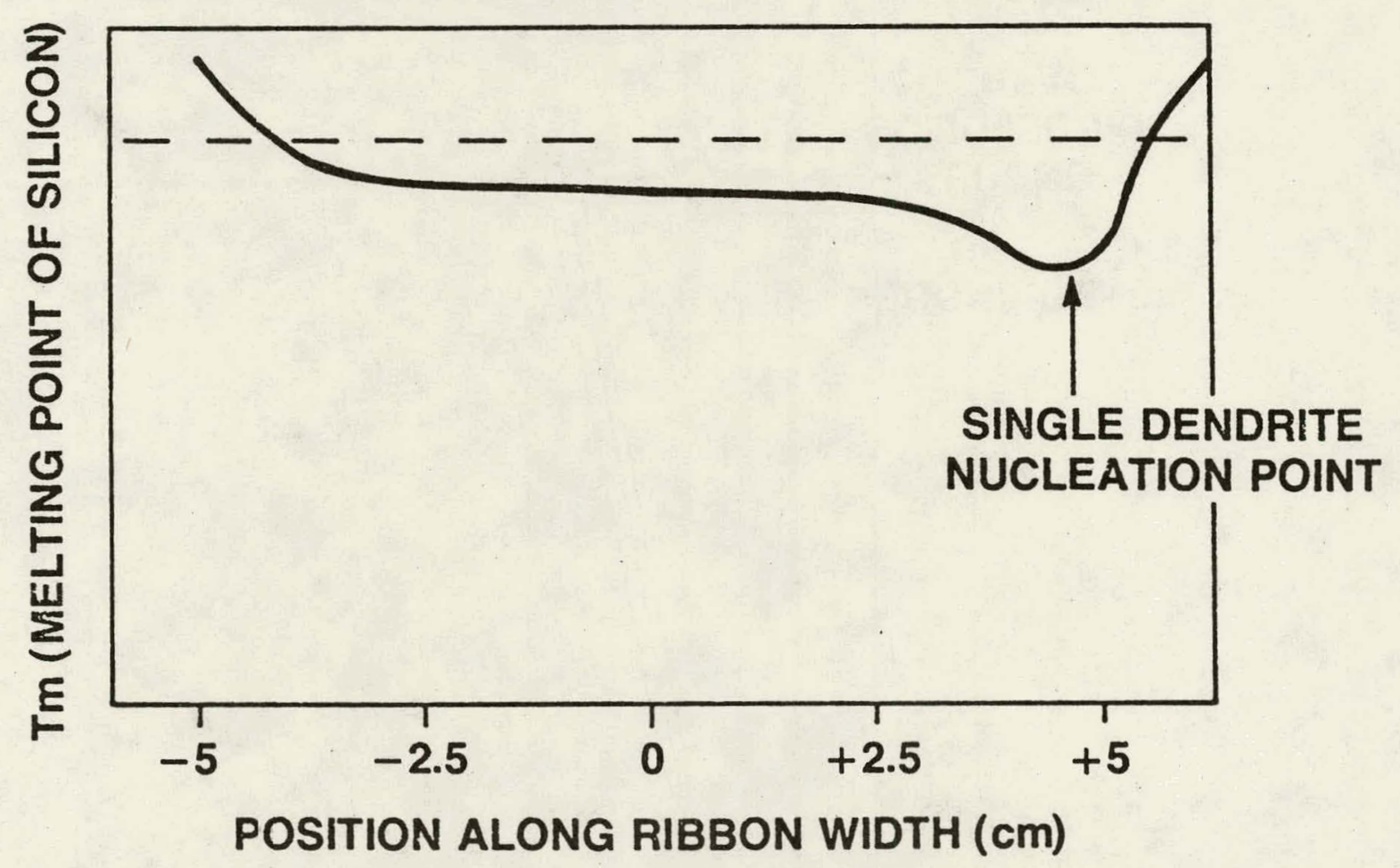

FIGURE 20: Temperature profile across ribbon width. 


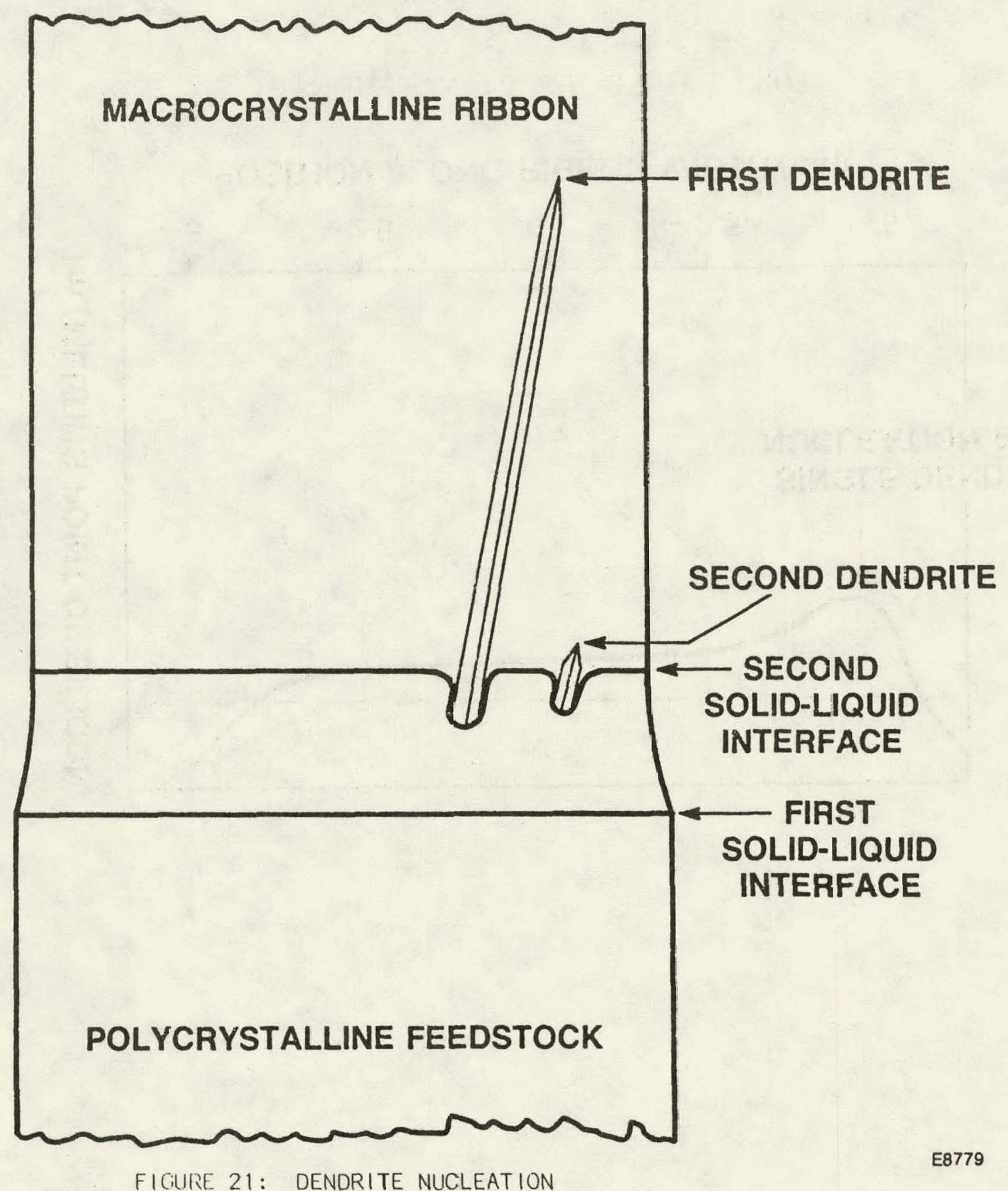



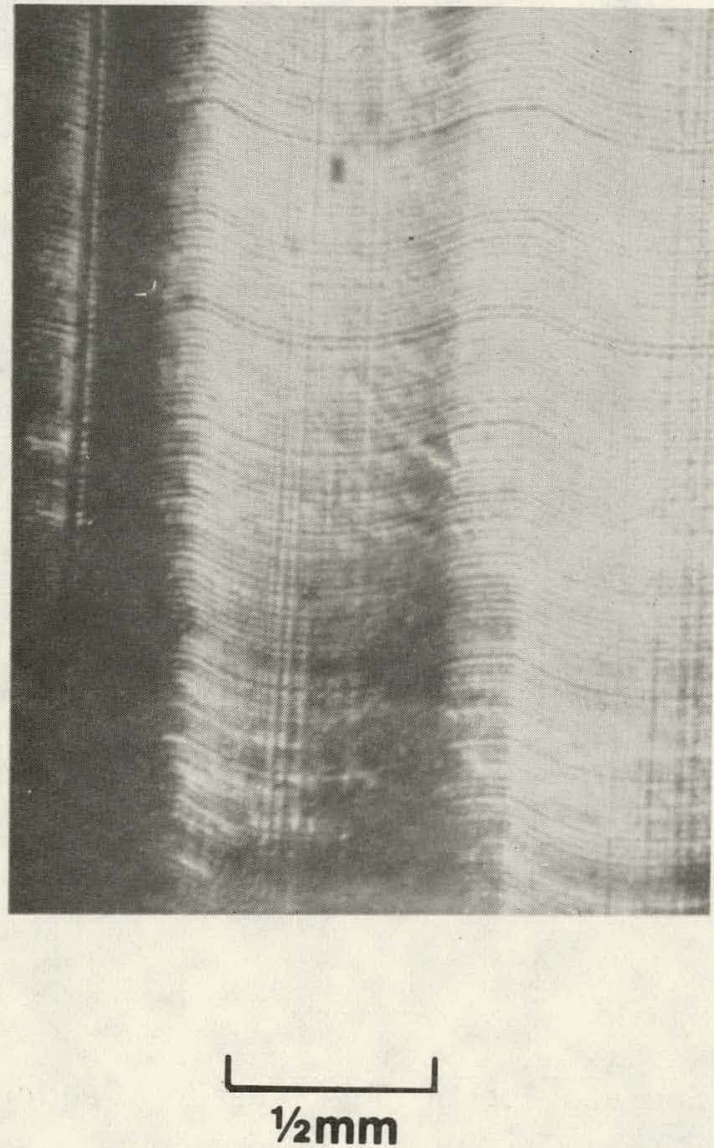

E8781

FIGURE 22: Surface Topography - Controlled Dendrite Growth 


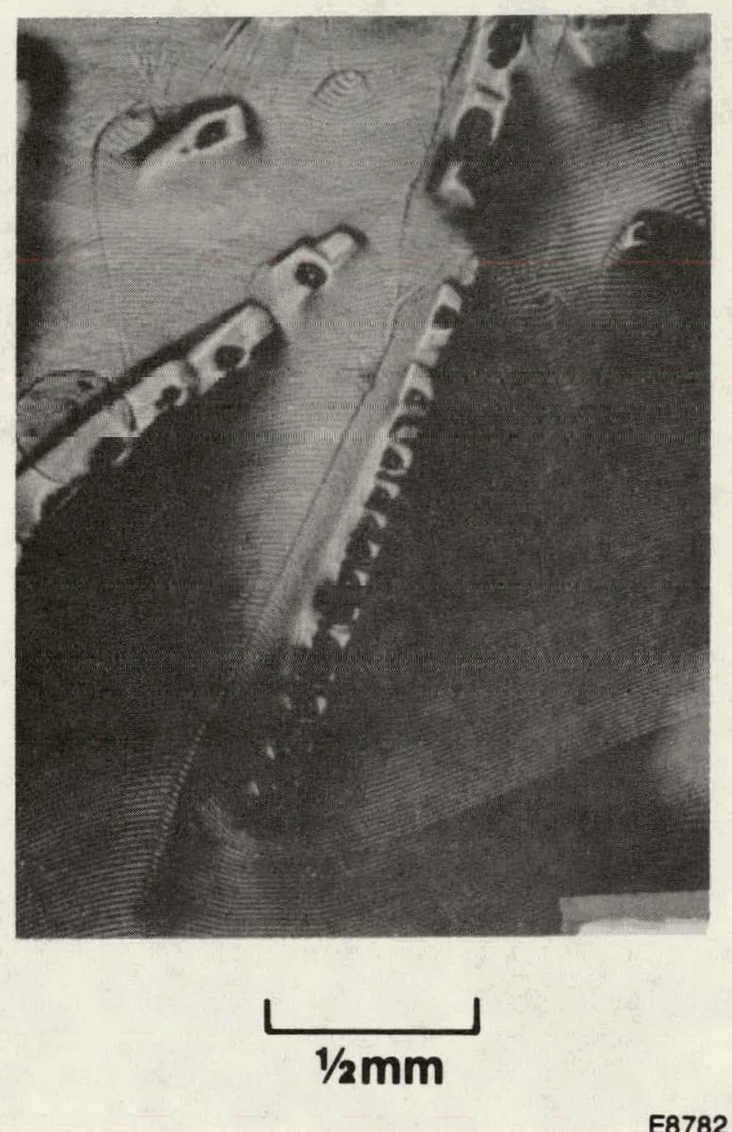

FIGURE 23: Surface Topography - Random Dendrite Growth 
significantly to the generation current. By contrast, planar defects under the dendrites are relatively benign. Figure 26 is an end view of such a defect, taken at $50^{\circ}$ incidence. The etching depth was only $~ 6 \mu \mathrm{m}$, indicating a relatively low energy defect. These qualitative conclusions are in agreement with measurements of the electrical activity of these defects taken with an SEM in the EBIC mode [16]: grain boundaries are strongly active, while twin planes/stacking faults are not detected.

These SEM micrographs show that, with controlled dendritic growth, the more harmful defects (grain boundaries, high density dislocations) are concentrated in a narrow area between dendrites, covering roughly $10 \%$ of the total available area. Previous measurements have shown that in the worst case, such areas still generate $50 \%$ of the potential photocurrent [17]. Thus the overall generation current loss due to high defect areas between the dendrites is on the order of $5 \%$. 


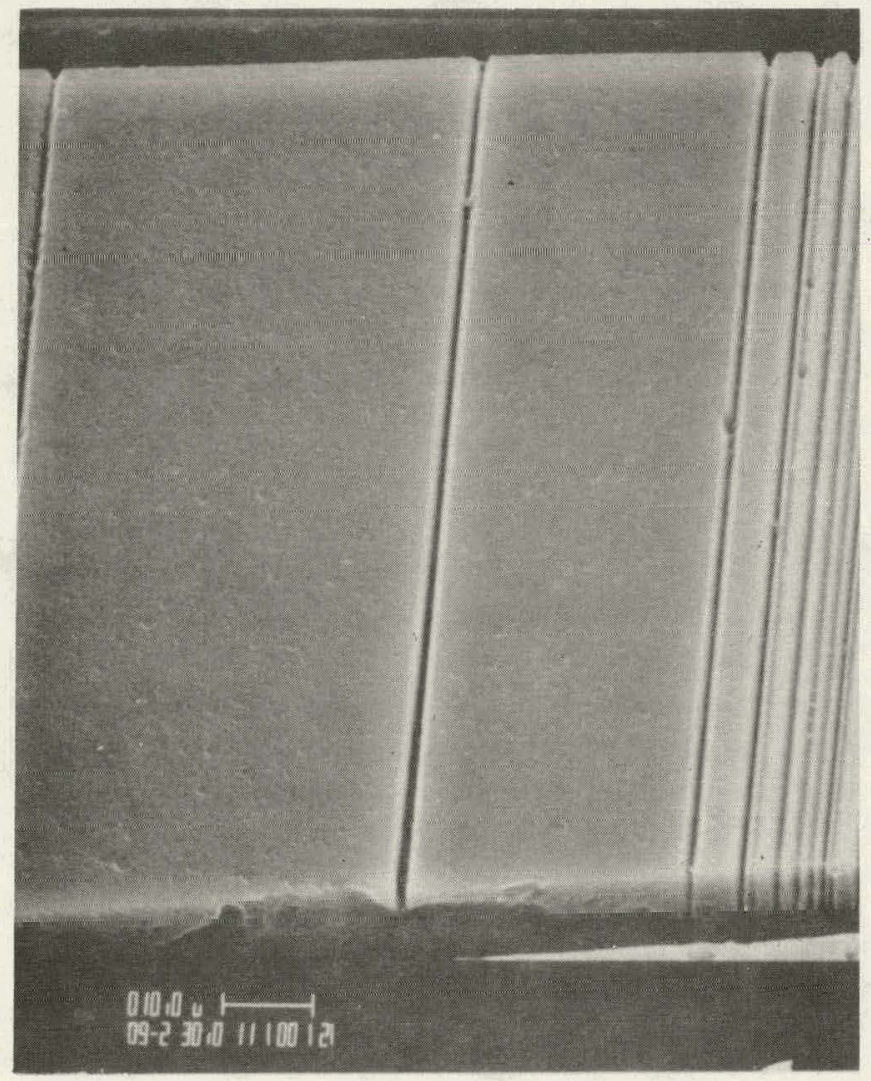

FIGURE 24: Dendrite Microstructure 


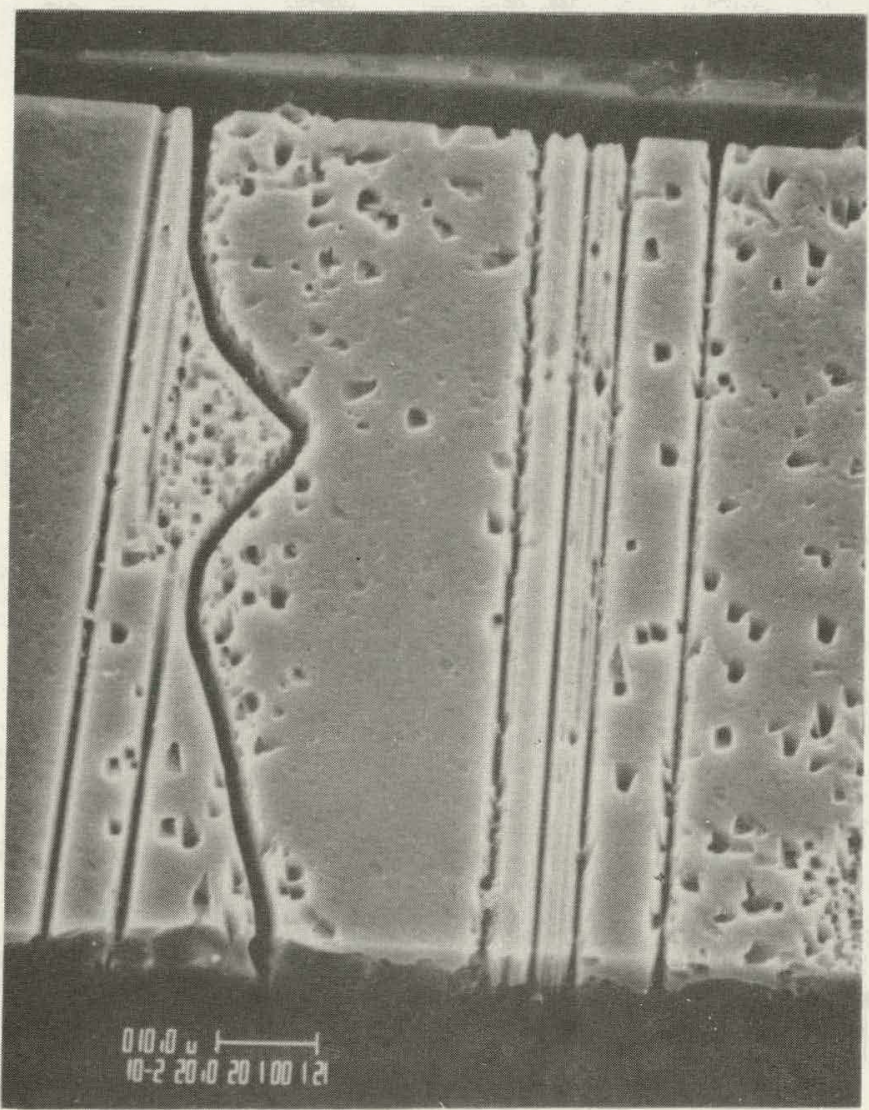

E8784

FIGURE 25: Grain Boundary 


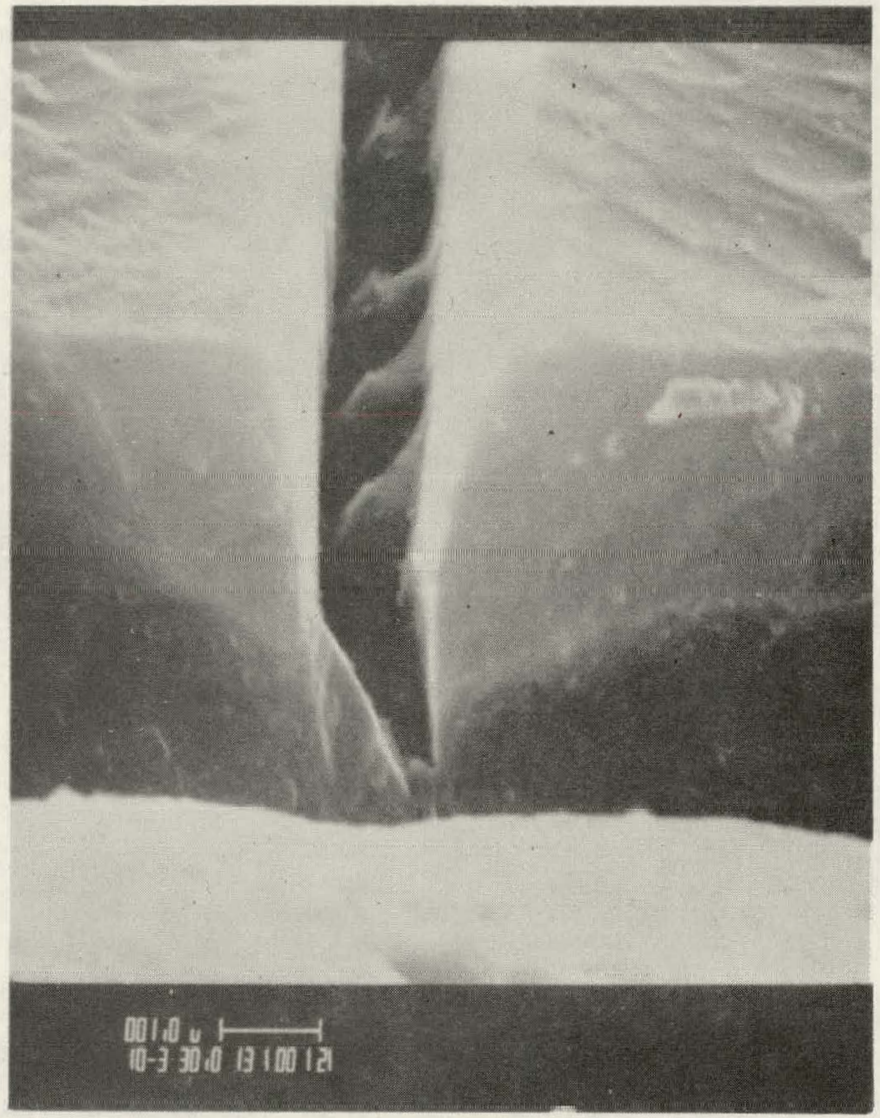

E8785

FIGURE 26: End View of Planar Defect 
Investigations are being made into the possibility that a tape casting technique might be utilized to provide an economical source of polyribbon. This would be an alternative to the TESS technique and would represent a distinct different technical approach.

The tape casting process is highly developed and is utilized commercially to provide thin substrates such as alumina and beryllia. It is routine in these technologies to produce $0.1^{\prime \prime}$ thick, 4" square substrates. The process is very economical and capable of high volume processing.

In tape casting of silicon, the following sequence is proposed:

1) Vapor nucleation of small silicon particles will be utilized to provide low cost silicon powder of about $10 \mu \mathrm{m}$ diameter. Numerous silicon purification processes are capable of this step. (e.g. Union Carbide free space reactor) Reasonable precautions will be taken to minimize oxide growth.

2) A suitable (see below) binder will then be utilized to produce a homogeneous slurry of silicon under controlled conditions.

3) Silicon tape will then be cast into the desired width and thickness by a conventional doctor blade apparatus onto a suitable conveyor belt. Mylar is a conventional choice but teflon is an attractive alternative.

4) "Drying" or "setting" of the binder system is achieved by controlling the environment around the belt.

5) Separation from the belt is effected when the tape has set.

6) "Burn-off" of the binder is now achieved through volatilization at a relatively low temperature and then oxidation at a somewhat higher temperature. 
7) Sintering of the silicon tape in a reducing atmosphere to increase the strength and density of the tape and to reduce the oxygen content.

8) Densification of the tape via vapor phase growth onto the ribbon.

Steps $2-6$, which involve the formation of the tape, are very simple and low cost. The key questions are purity of the resulting silicon tape, and the necessity of step $\# 8$, densification.

The purity of the resulting silicon will, for the most part, be dictated by the choice of a binder and the burn-off procedure. It seems very probable that a binder can be developed which can be totally volatilized and oxidized. Use of distillation processes to obtain a very high purity binder initially, should reduce residual impurities to acceptable levels.

Step \#8, densification, may or may not be necessary. Previous experimentation has indicated that it would be required.

Some investigations have been initiated which will attempt to determine the basic feasibility of this process. The feasibility of producing sintered silicon tape has al ready been verified since ithas been found that Airesearch Casting Company (a division of Garrett) has previously produced such tape. Their application, however, is for production of silicon nitride tape and purity is not a major concern. To test the feasibility of this tape for our process, we will supply Airesearch with high purity silicon powder to be tabricated into silicon tape. Precautions will be taken to choose a high purity binder and a burn off -sintering cycle which should provide silicon tape of high purity. We will subsequently attempt to regrow these tapes with or without the densification procedure. If growth is successful, electrical evaluations will then be made. 
The RTR process is similar to float zone crystal growth in that the molten silicon is not in contact with a container or die which might contaminate it. Thus the main source of impurities is the polyribbon feedstock itself. At present, the polycrystalline feedstock is grown by chemical vapor deposition on a molybdenum substrate. Neutron Activation Analysis (N.A.A.) on CVD feedstock has shown Mo contamination in the range of $5-20$ ppmw $\left(\sim 10^{16} / \mathrm{cm}^{3}\right)$. R. H. Hopkins and co-workers have shown that Mo impurities at a concentration as low as $10^{12} / \mathrm{cm}^{3}$ reduce the cell efficiency by $15 \%$ [18]. Thus, for high efficiency solar cells, the Mo level may have to be reduced by several orders of magnitude.

Mo may be incorporated into the Si ribbon by several mechanisms: Mo vaporization, caused by plasma arcing due to high RF fields in the reaction chamber; autodoping due to chlorine transport of Mo; or solid-state diffusion from the Mo substrate directly into the silicon ribbon, possibly along the grain-boundaries of the polycrystalline silicon.

The first two mechanisms would result in Mo distributed randomly (in the case of Mo vaporization), or uniformly in the bulk of the silicon ribbon (in the case of autodoping). Secondary Ion Mass Spectroscopy, however, has shown a strong dependence of the Mo concentration on distance from the Mo-Si interface (See Figure 27). This positional dependence implies that direct solid-state diffusion across the Mo-Si interface may be a primary mechanism for Mo doping of the silicun ribbon.

In an initial experiment, $1-2 \mathrm{mils}$ were removed from the silicon ribbon surface by different techniques: $\mathrm{HCl}$ vapor etch, mechanically 
polishing the ribbon surface, wet chemical $\left(\mathrm{HNO}_{3}, \mathrm{HF}\right.$, Acetic Acid) etch, and plasma etching in a $\mathrm{CF}_{4}-\mathrm{O}_{2}$ glow discharge [19]. Neutron Activation Analysis showed that both the chemical etch and the plasma etch reduced the Mo impurity level to below the N.A.A. detection limit ( 1 ppmw Mo in this case).

Ahother approach for reducing the Mo contamination is to deposit a diffusion barrier onto the Mo belt prior to silicon deposition. Silicon nitride was chosen as the diffusion barrier since it is easy to deposit, does not introduce a new element into the system and is an excellent diffusion barrier [201. An $800-850 \AA$ layer of silicon nitride was deposited at $750^{n} \mathrm{C}$ : using low pressure chemical vapor deposition. A silicon ribbon was then deposited on the $\mathrm{Si}_{3} \mathrm{~N}_{4}$-Mo belt using standard deposition conditions. The polyribbon separated intact from the $\mathrm{Si}_{3} \mathrm{~N}_{4}-\mathrm{Mo}$ substrate. The polyribbon was then routinely re-grown, using the RTR apparatus at $11 / \mathrm{min}$. The first photovoltaic cell was recently fabricated on this material, (See Section 6.0). It had an efficiency of $6 \%$, with $I_{S C} \sim 16.4 \mathrm{~mA} / \mathrm{cm}^{2} . V_{O C} \sim 0.54$ volts. These results are significantly improved over ribbons grown from unprotected feedstock, which typically have $n \sim 4 \%$. However, the efficiency is still low, indicating that further progress needs to be made.

The $\mathrm{Si}_{3} \mathrm{~N}_{4}$ coating has the additional benefit of protecting the Mo substrate from exposure to $\mathrm{Si}$ or $\mathrm{SiH}_{x} \mathrm{Cl}_{y}$ vapor. This should greatly extend the useful life of the Mo substrate.

The use of a $\mathrm{Si}_{3} \mathrm{~N}_{4}$ coating on Mo substrates may introduce new problems. One possible problem area may be microcracks in the $\mathrm{Si}_{3} \mathrm{~N}_{4} \mathrm{film}$. Figure 28 is a photograph of such a.crack in the $\mathrm{Si}_{3} \mathrm{~N}_{4}$ film after deposition and separation. The microcracks were few and far apart; their width is 


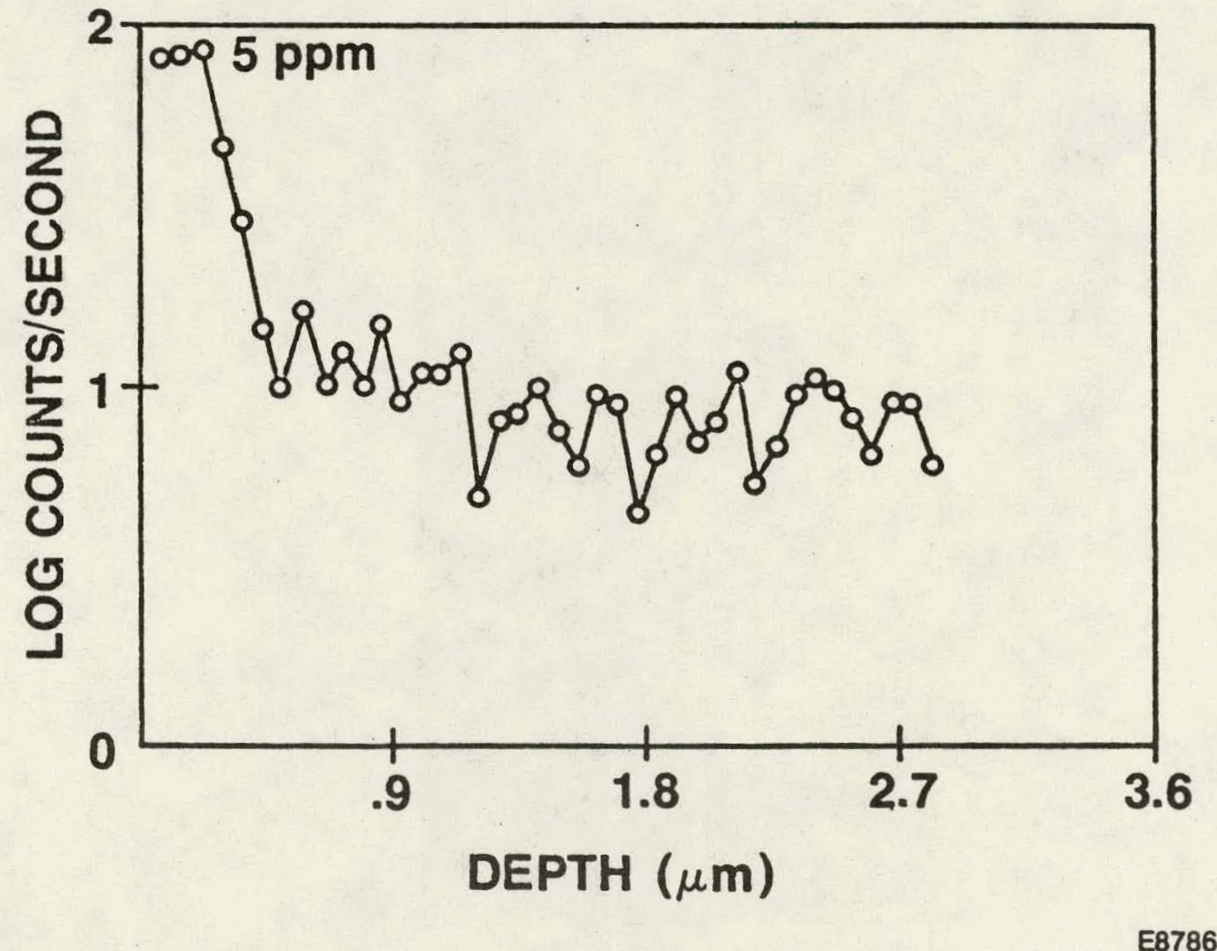

FIGURE 27: Mo Concentration - Depth Profile 


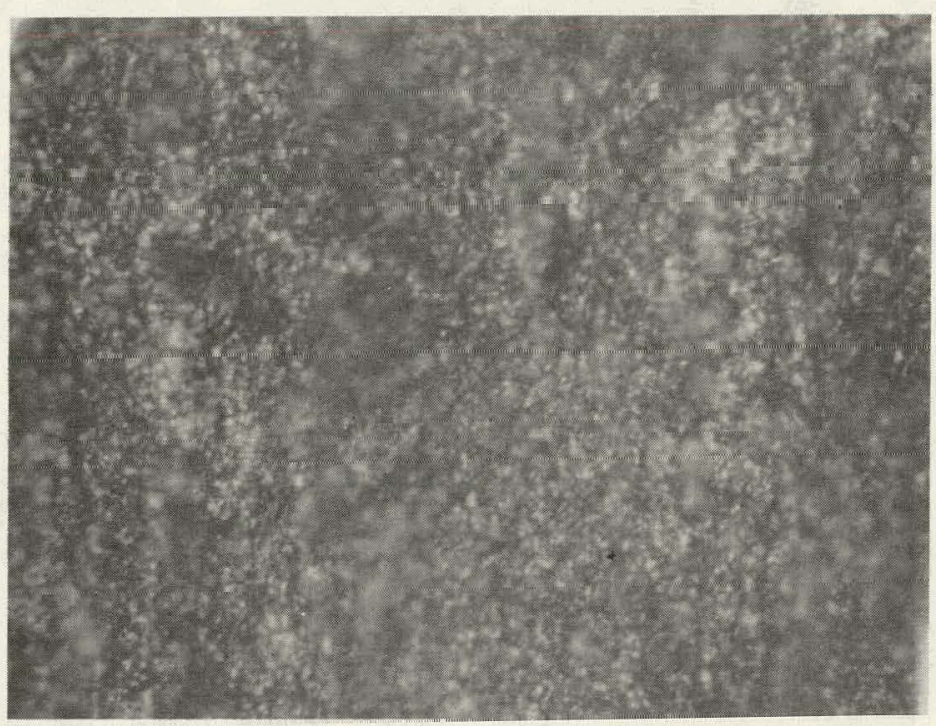

FIGURE 28: Micrnerack in $\mathrm{Si}_{3} \mathrm{~N}_{4} \mathrm{Fi} / \mathrm{m}$ (440X magnification) 
estimated to be less than $200 \AA$. At the density and distribution at which they were observed on this sample, however, they should not pose a serious problem. However, if they propagate and multiply during subsequent deposition, we might have to remove the $\mathrm{Si}_{3} \mathrm{~N}_{4}$ film and redeposit it after every cycle.

An Auger analysis of a Mo substrate after one deposition and removal of $\mathrm{Si}$ revealed that there was no Mo exposed, only $\mathrm{Si}, \mathrm{SiO}_{2}$ and $\mathrm{Si}_{3} \mathrm{~N}_{4}$.

The Mo substrate might also be the source of impurities other than Mo.

General Activation Analysis, Inc. did succeed in detecting Au in RTR samples, at levels ranging from $1-3$ ppbw. Since the control Czochralski sample also contained Au at that level, Au is probably not significantly responsible for the low photoresponse on RTR silicon.

57 


\subsection{THE MEASUREMENT OF SHORT DIFFUS ION LENGTHS}

The OCPV or SPV methods for measuring diffusion lengths cannot be used to measure diffusion lengths below $~ 5 \mu \mathrm{m}$ [21]. We have applied another method, first used by Logan and Chynoweth on GaP homojunctions [22], to the measurement of diffusion lengths in silicon ribbon. This technique, referred to here as the Depletion Width Modulation. (DWM) method, relies on the measurement of the difference between the photocurrent generated by long wavelength, monochromatic Iight, and the dark current under reverse bias.

Data for sample 784-1 (for AMl conditions, $J_{S C}=13.0 \mathrm{ma} / \mathrm{cm}^{2}, v_{o c}=0.49$ and a fill factor of $75 \%$ are shown in Figure 29. The data is an excellent fit to a straight line, confirming the validity of our assumptions. The diffusion length in this case is $2.68 \mu \mathrm{m}$. The diffusion length and $\mathrm{J}$ sc are listed in Table 1 for three solar cells fabricated on re-grown CVD silicon. Table 1 also contains the carrier concentration of the RTR samples. These data were obtained by plotting $C(V)^{-2}$ vs. V. Since [23]

$$
\frac{d\left(\frac{A^{2}}{C^{2}}\right)}{d V}=2\left(N_{A} q \varepsilon\right)^{-1}
$$

$N_{A}$ can be calculated from the slope of $\mathrm{C}^{-2}$ vs. $\mathrm{V}$.

The variation in the measured carrier concentration is small, both from sample-to-sample and along the length of a single ribbon. Moreover, the measured doping level is very close to our target during the CVD process:

$$
N_{A}(\text { meas. }) \simeq 2 \times 10^{16} / \mathrm{cc}, N_{A}(\text { goal }): 1.5 \times 10^{16} / \mathrm{cc}
$$

These tolerances compare well with the variation which occurs with Czochralski silicon.

The: photocurrent of an n+-p cell consists of three components: 
Photocurrent (for $\lambda=950 \mu \mathrm{m}$ $\mu \mathrm{A} / \mathrm{cm}^{2}$

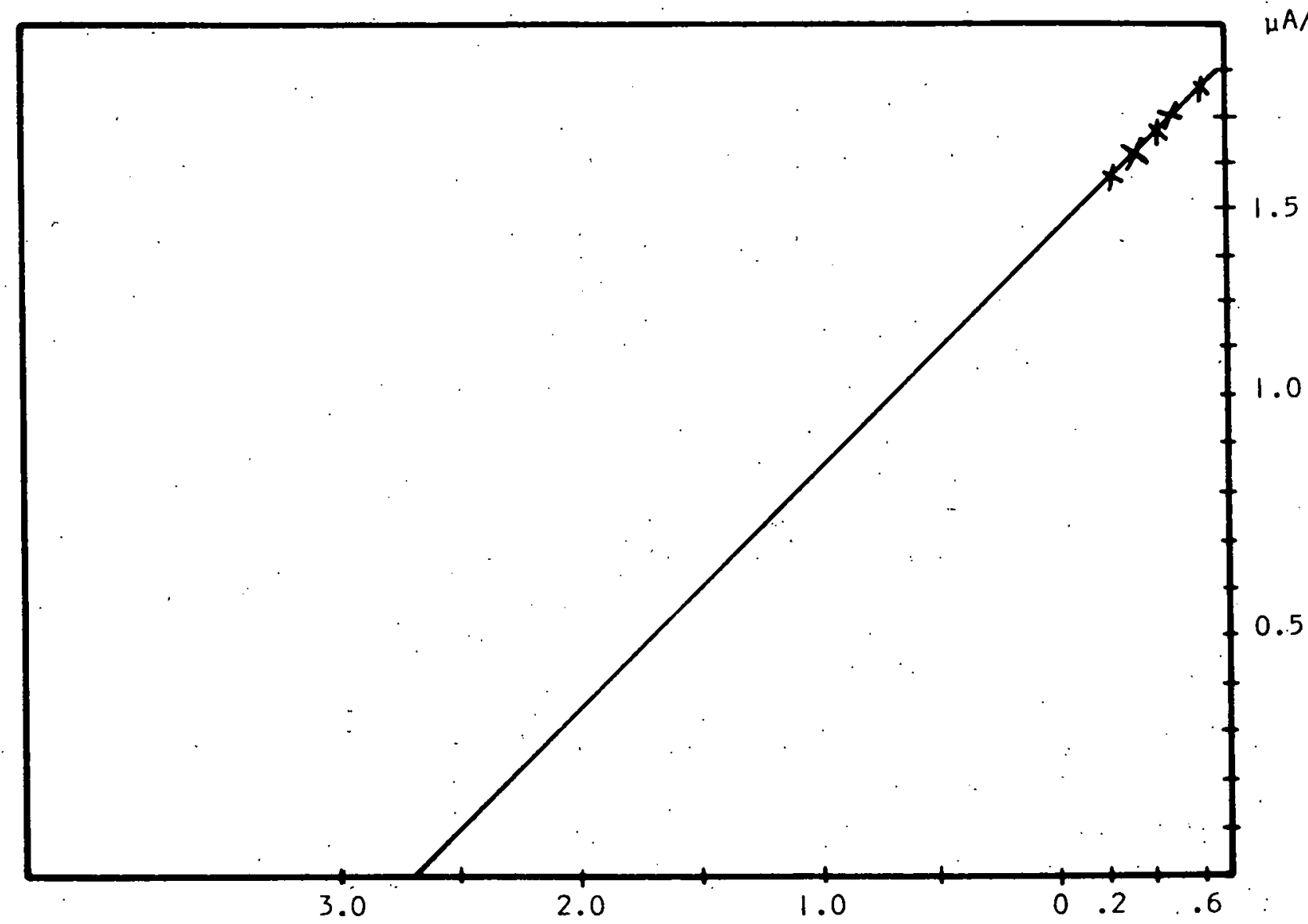

DEPLETION REGION WIDTH W ( $\mathrm{Wm}$ )

HICLIRE 29: DIFFUSION LENGTH MEASUREMENT BY DWM - SAMPLE 784-1 
1) Hole current collected from the generation of electron-hole pairs in the $n+$ region.

2) Current collected from electron-hole pairs generated within the depletion region.

3) Electron current collected from electron-hole pairs generated with in the bulk of the p-type substrate.

For the case of uniform generation of carriers - i.e. for long wavelength light - the first contribution is negligible because the diffusion length in the thin, heavily doped $n+$ region is very short. So, neglecting the term due to hole generation, the photocurrent can be given by:

$$
J_{\text {photo }} \alpha W+L_{e}
$$

where $L_{e}$ is the electron diffusion length in the p-region

$W$ is the depeltion region width (the substrate thickness is much greater than its diffusion length).

The width of the depletion region. is given by:

$$
W(v)=\left(\frac{2 t\left(V_{b} \neq v\right)}{q N_{A}}\right)^{\frac{1}{2}}
$$

where $V$ is taken as positive for reverse hias. The photocurrent will thon increase with reverse bias. A plot of J photo vs. W will have an intercept, for $J_{\text {photo }}=0$, at $W=-L_{e}$.

The experimental procedure is then to first obtain $W(V)$ by measuring the capacitance - voltage characteristics:

$$
W(V)=\frac{\varepsilon A}{C(V)}
$$

Then, by plotting the photocurrent as a function of $W(V)$ the diffusion length can be determined. 
TABLE 1: PHOTOVOLTÁIC DEVICE DATA

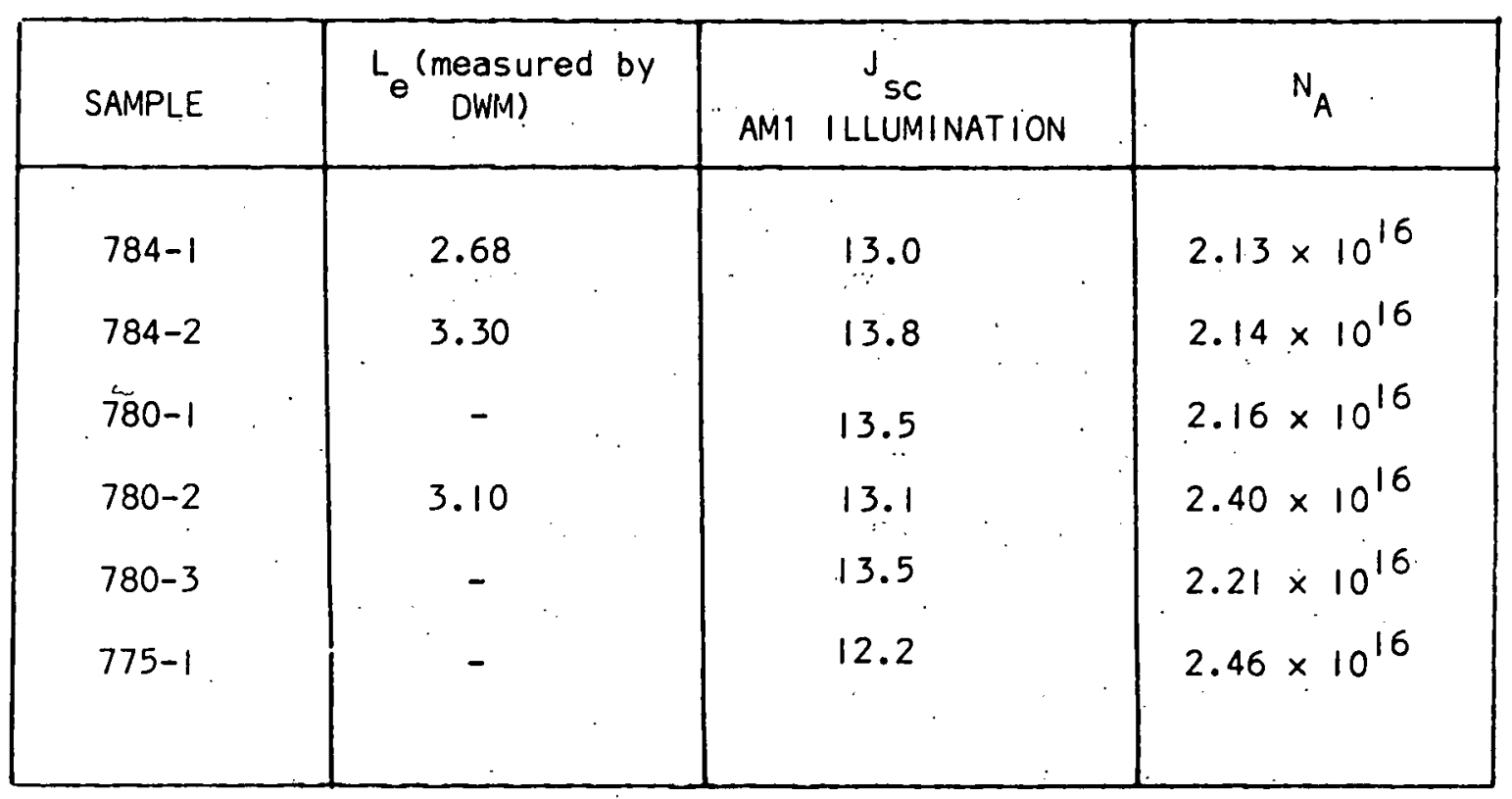


The first lot of solar cells made from QVD feedtock (grown on bare Mo substrate) has been fabricated, and efficiencies measured. The results are summarized in Table 11 . The maximum nominal efficiency of 5\% is disappointing, of course, but three important points should be made:

1) Of the three fundamental solar cell parameters affecting efficiency, $V_{O C}$, JSC and fill factor, the better cells of this lot were well above average in fill factor (74 vs 61\%), above average in $V_{O C}(.490$ vs. .478) but deficient in J SC (13. vs. 26.); all compared to the better cells made on regrown single crystal feedstock. The fill factor, which in conjunction with the open circuit voltage, is a measure of the leakage current present in the solar cell junction provides a very encouraging picture. A semilogarithmic plot of the dark current-voltage characteristics for an RTR solar cell from regrown single crystal feedstock $\left(n=9 \%, V_{O C}=.49, J_{S C}=29.1, F F=65 \%\right)$ is compared with a cell made from regrown CVD feedstock $\left(n=4.9 \%, v_{O C}=.494, J_{S C}=13.1\right.$, $F F=76 \%$ ) in Figure 30 . As can readily be seen, leakage current in the CVD cell is much lower.

2). The short curcuit current is so much smaller than expected that the only reasonable cause could be very short minority carrier diffusion length. A short circuit current of less: than $15 \mathrm{~mA} / \mathrm{cm}^{2}$ puts an upper I imit on the diffusion length of $20 \mu \mathrm{m}$. Since diffusion lengths (and short circuit currents) are commonly seen to be much larger on solar cells made from regrown single crystal feedstock, the cause is almost certainly some kind of chemical contamination in the CVD feedstock. This is consistent with neutron activation analyses which have shown Mo impurity levels in the range of $5-20$ ppmw.

3). This lot of cells was made by a planar process which was thought to be superior to the mesa process used in the past. This may not be the case. The control cells, consisting of 4 - 6 inch long slabs of single crystal (100) Czochralski silicon, which were processed along with the CVD ribbons, were 
SOLAR CELLS FABRICATED ON RTR SILICON GROWN FROM CVD FEEDSTOCK

Planar process, using $\mathrm{Si}_{3} \mathrm{~N}_{4}$ masklng, $\mathrm{Pd} / \mathrm{Ni}$ metallization.

Cell Area: $4 \mathrm{~cm}^{2}$

\begin{tabular}{|l|l|l|l|l|}
\hline CELL 1.0. & $V_{O C}(\mathrm{vol}+\mathrm{s})$ & ${ }_{\text {SC }}\left(\mathrm{mA} / \mathrm{cm}^{2}\right)$ & $F F$ & $\eta$ (AMI) \\
\hline $789-2$ & 0.494 & 13.1 & 0.76 & 4.9 \\
$789-1$ & 0.490 & 13.0 & 0.75 & 4.8 \\
$791-1$ & 0.490 & 13.8 & 0.70 & 4.7 \\
$718-F-1$ & 0.505 & 14.2 & 0.61 & 4.35 \\
$776-3$ & 0.493 & 12.8 & 0.68 & 4.3 \\
$780-2$ & 0.487 & 13.8 & 0.63 & 4.2 \\
$780-3$ & 0.486 & 13.5 & 0.63 & 4.1 \\
$782-4$ & 0.486 & 12.8 & 0.64 & 4.0 \\
$773-2$ & 0.485 & 13.3 & 0.60 & 3.9 \\
$775-1$ & 0.489 & 12.2 & 0.64 & 3.8 \\
$780-1$ & 0.490 & 13.5 & 0.54 & 3.6 \\
$776-2$ & 0.496 & 12.1 & 0.57 & 3.4 \\
$777-3$ & 0.473 & 12.9 & 0.52 & 3.2 \\
$784-1$ & 0.488 & 11.4 & 0.57 & 3.2 \\
$775-2$ & 0.477 & 12.8 & 0.49 & 3.0 \\
& & & & \\
\hline Control & 0.515 & 26.0 & 0.74 & 10 \\
\hline Czochraiski & & & & \\
\hline
\end{tabular}




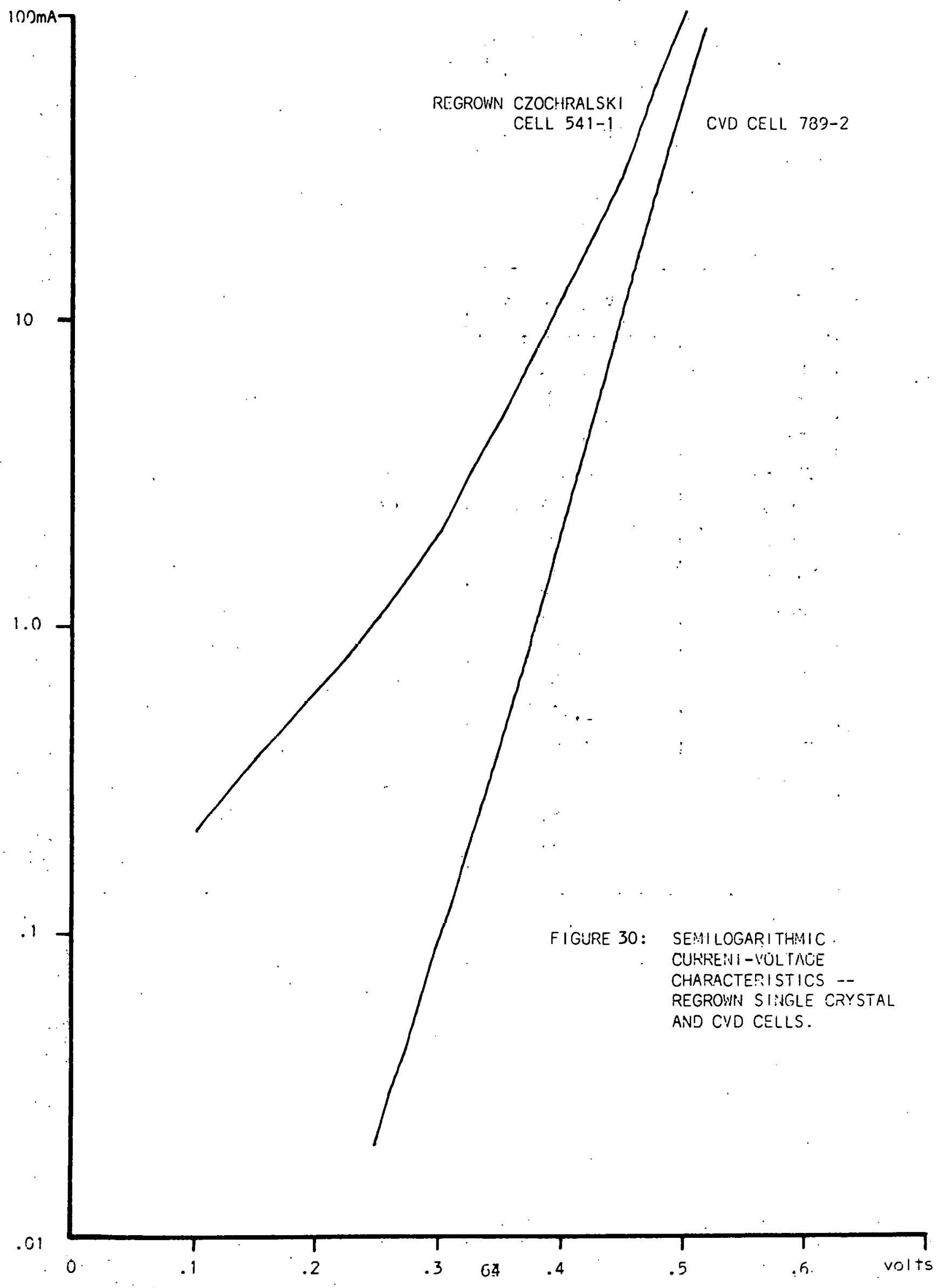




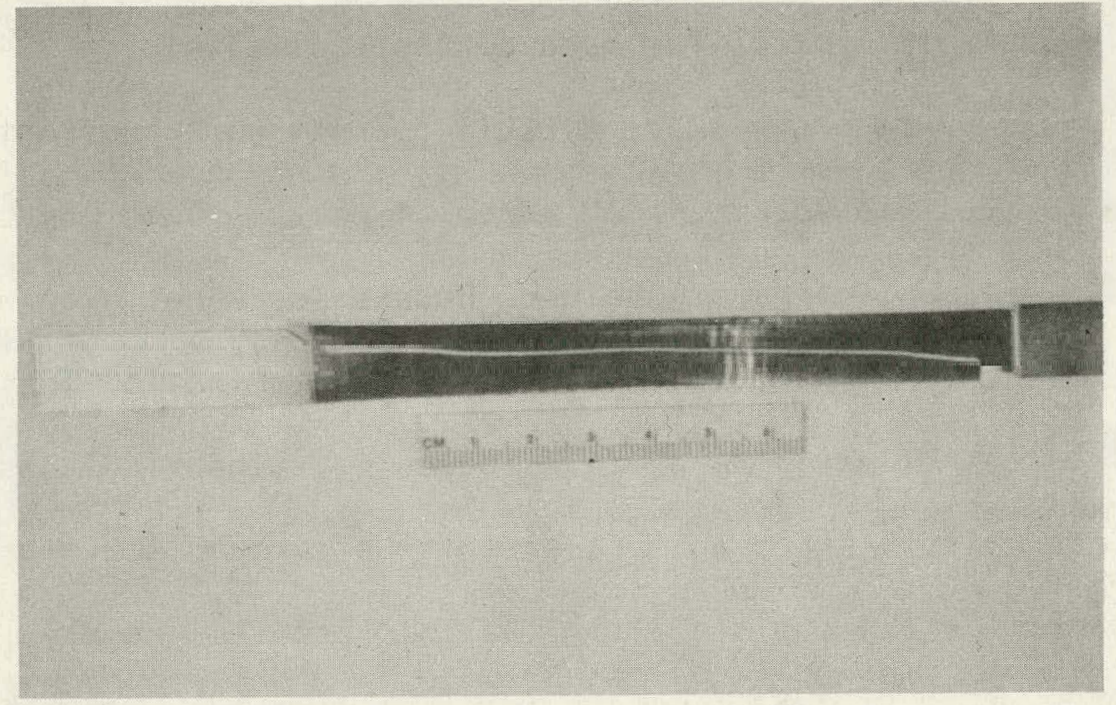

FIGURE 31a: RIBBON FRACTURE -- PARALLEL TO GROWTH

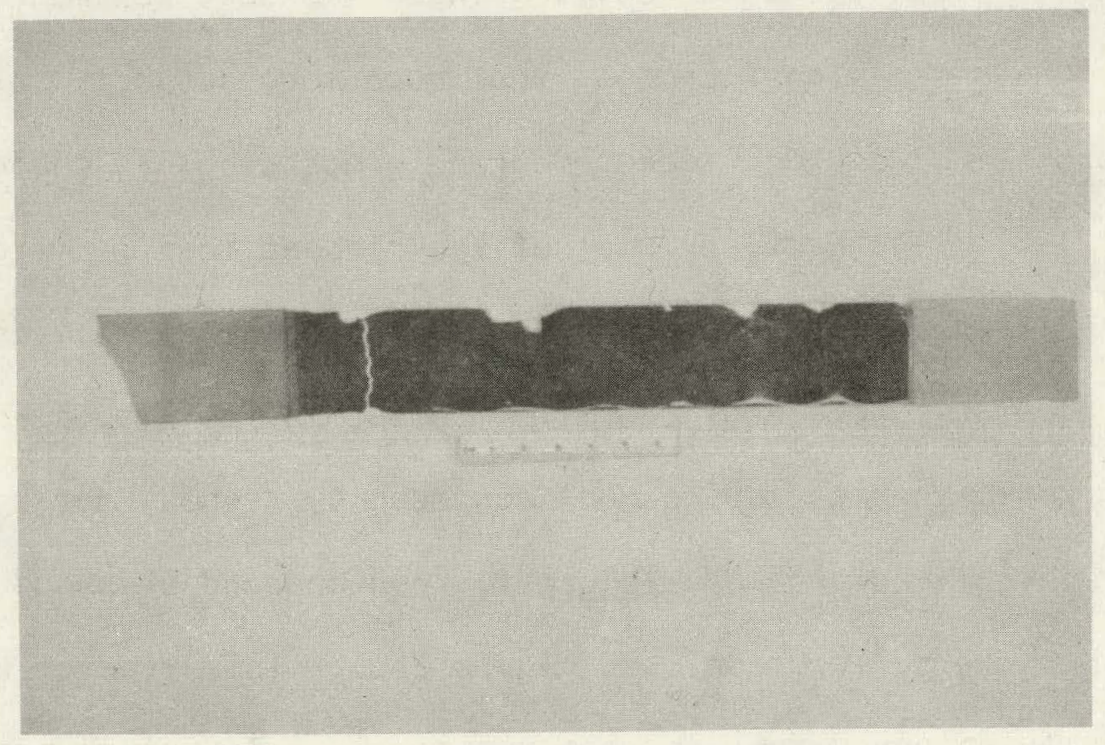

FIGURE 31b: RIBBON FRACTURE -- NORMAL TO GROWTH 
well below average also. The control cells averaged $10 \%$ efficiency compared to a usually seen efficiency (for mesa control cells) of $13-14 \%$. Both the open circuit voltage and short circuit current were substantially lower, .52 vs. .56 for $\mathrm{V}_{\mathrm{OC}}$ and 26 . vs. $>30 \mathrm{~mA} / \mathrm{cm}^{2}$ for $\mathrm{J}_{\mathrm{SC}}$. This may be due to the mesa process being an inherently better process sequence. There is also a slight possiblity that the suspected chemical contamination in the CVD ribbons spread to the control material during processing. The first possiblity seems much more likely since an earlier lot run through the planar process had control cells which, suffered from the same problem, namely lower $V_{O C}$ and $\mathrm{J}_{S C}$. Other lots of CVD ribbons ( $p /$ us controls) are being fabricated by the mesa process for comparison.

While the open circuit voltages for this lot of CVD ribbons were typical of single crystal feedstock (regrown), ribbons, it was somewhat lower than that observed in our first CVD solar cell. Since this cell was made by the mesa process, it makes the planar process that much more suspect.

The problem of ribbon breakage during processing has changed in character in the last few lots. Earlier, most of the ribbons that broke during handling did so by splitting lengthwise (parallel to the growth direction, see figure 31a). This is attributed to residual thermal stresses in the ribbon which weakened it. With the improved thermal environment now seen by ribbons during growth, the thermal stress-related breakage is greatly reduced and breakage now occurs normal to the growth direction (see Figure $31 \mathrm{~b}$ ). This type of breakage is very frequently observed now, and has two causes. The first and most important is breakage during the blow-dry operation following each wet chemical step. This is being reduced by the use of $\mathrm{O}_{2}$ plasma clean or $\mathrm{CF}_{4}-\mathrm{O}_{2}$ plasma etch cycles where appropriate, since they are gaseous operations not 
requiring a drying step. Also, for steps in the processing which do require a drying step (following an ultra pure deionized water rinse), an alternate drying procedure will be used. Instead of a forced nitrogen blow-dry step which is a one-ribbon-at-a-time process that stresses the ribbon and causes fractures, a much more gentle, multiple ribbon drying step using a freon vapor degreaser system will be used. This should reduce breakage substantially, and increase the number of ribbons that can be processed (or increase the speed of processing ribbons).

There is a second source of ribbon breakage which has received attention, and that is due to the excess weight of the un-regrown tabs of CVD feedstock which accompany every CVD ribbon. These are $1-2$ inches of dead weight. microcrystalline silicon which weighs down the ribbon particularly when picked up in the center, and exerts stress resulting in fracture. We intend to scribe: tabs off using a YAG laser scriber apparatus. The YAG will also be used for cutting regrown ribbons to uniform lengths, particularly for the ion implanter, which will not take samples longer than 7 inches. YAG scribing has been used successfully on CVD feedstock, macrocrystalline regrown ribbons, and, of course, single crystal silicon.

\subsection{SOLAR CELLS - FEEDSTOCK GROWN ON $\mathrm{Si}_{3} \mathrm{~N}_{4}-$ COATED SUBSTRATE.}

In Section 4.0, we described the use of $\mathrm{Si}_{3} \mathrm{~N}_{4}$ as a diffusion barrier to prevent contamination of the silicon ribbon by Mo. One solar cell has been fabricated on RTR silicon re-grown from feedstock deposited on an $\mathrm{Si}_{3} \mathrm{~N}_{4}$ coated Mo substrate. This cell had an efficiency of 6\%, with $v_{O C}=0.545, J_{S C}=16.4 \mathrm{~mA} / \mathrm{cm}^{2}$ and a fill factor of $67 \%$. The short circuit current is still too low, indicating that the diffusion barrier was not $100 \%$ 
effective in preventing Mo contamination. This was confirmed by Neutron Activation Analys is which indicated 15.6 ppmw of Mo in another sample grown from polyribbon deposited on $\mathrm{Si}_{3} \mathrm{~N}_{4}$ coated substrate. Theșe results indicate incomplete coverage of the Mo substrate. We will continue these experiments, optimizing the uniformity of the $\mathrm{Si}_{3} \mathrm{~N}_{4}$ coating and increasing its thickness. 


\section{REFERENCES}

1. R. W. Gurtler, A. Baghdadi, R. J. Ellis, and I. A. Lesk, J. Electronic Materials, Vol. 7, No. 5, (1978), 441.

2. A. Baghdadi, R. W. Gurtler, R. N. Legge, R. J. Ellis, and B. L. Sopori, Proceedings Thirteenth IEEE Photovoltaic Specialists Conference, (1978), 363.

3. A. D. Morrison, K. V. Ravi, C. V. Hari Rao, T. Surek, D. F. Bliss, L. C. Garone, and R. N. Hogencamp, Annual Report, ERDA/JPL 954355/ $76-11$ (1976) 11 .

4. M. M. Myshlyaev, V. 1. Nikitenko, and V. 1. Nesterenko, Phys. Sțat. Sol., 36, (1969), 89.

5. C. D. Graham, Jr., S. Kulkarni, G. T. Noel, D. P. Pope, B. Pratt and M. Wolf, 2nd Quarterly Report, ERDA/JPL-954506-76/2 (1976).

6. W. D. Sylwestrowicz, Phil. Mág., Ser. 8, Vol. 7, (1962), 1825.

7. J. R. Patel and A. R. Chaudhurl; J. App. Phy. Vol 34, No. 9, (i963), 2788.

8. B. A. Boley and J. H. Weiner, in: Theory of Thermal Stresses (Joh'n Wiley and Sons, N.Y., 1960) 261.

9. B. A. Boley and J. H. Weiner, Op. Cit., 323.

10. K. S. Kunz, in: Numerical Analysis (McGraw-Hill, N. Y., 1957), 2.75 .

11. R. W. Gurtler, A. Baghdadi, Technical Quarterly Report No. 2, ERDA/JPL $954376-76 / 2,1976,25$.

12. A. Baghdadi, Proceedings: Ninth Project Integration Meeting, LSA Project $(5101-67),(1978), 3-89$.

13. R. W. Gurtler, A. Baghdadi, R. Legge, B. Sopori, and R. J. Ellis, Technical Quarterly Report No. 6, DOE/JPL 954376-78-1, (1977), 14.

14. P. Masser, Private Communication.

15. H. L. Cox, in: The Buckling of Plates and Shells (Pergamon Press, N.Y., 1963), 21 .

16. A. Baghdadi ct al., Thirleenth IEEE Photovoltaic Specialists Conference, Washington D.C., June 1978.

17. A. Baghdadi, R. W. Gurtler, R. Legge, B. Sopori, R. J. Ellis; Motorola Quarterly Report No. 8, DOE/JPL No. 954376-78/3, June 1978. 
18. R. H. Hopkins et. al., Westinghouse Quarterly Report No. 10, DOE/JPL No. 954331-78/2, March 1978.

19. H. F. Winters, J. W. Coburn, E. Kay, J. Appl. Phys., 48, (12), December 1977.

20. J. T. Milek, Silicon Nitride for Microelectronic Applications (IFI/Plenum, N. Y., 1971).

21. 1977 Annual Book of ASTM Standards, STD F391-37T.

22. Logan and Chynoweth, J. Appl. Phys. 33, p. 1649, (1962).

23. S. M. Sze, Physics of Semiconductor Devices, John Wiley and Sons, N. Y., (1969). 


\section{7.}

No new technical problems have been uncovered in this period. The Mo contamination problem is receiving continued attention. It is felt that this is the major limiting factor determining RTR solar cell efficiency. The open circuit. voltage and fill factor of solar cells fabricated on RTR grown CVD feedstock are satisfactory, but the short circuit current is far too low because of the very short diffusion lengths. Both pre-etching the CVD feedstock (before RTR growth) and growing the CVD polyribbon on a $\mathrm{Si}_{3} \mathrm{~N}_{4}$ coated substrate show potential for reducing the Mo impurity to an acceptable. level. 


\subsection{POLYCRYSTALLINE FEEDSTOCK}

We plan to carry out some preliminary experiments with silane as the source gas for CVD.formation of the polyribbon. These experiments will allow us to study the impurity level in polyribbon grown in a chlorine-free atmosphere. We will also study the effects of reducing deposition temperature on the efficacy of ribbon separation.

Wo aro also ro-cycling the Mo substrate (both bare and $\mathrm{Si}_{3} \mathrm{~N}_{4}$ coated) to determine its maximum lifetime.

\subsection{RTR GROWTH}

We are installing a new furnace to control the temperature profile in both heating and cooling of silicon ribbons. This furnace is completely sealed, and should allow improved impurity control during RTR crystal growth. We will also carry out high speed growth runs, with both single and multiple ribbon growth.

\subsection{SOLAR CELL PROCESSING}

Solar cells are now being made on re-grown CVD feedstock which has been pre-etched. This should result in less contamination and a higher short circuit current. Solar cells will also be started on feedstock deposited on $\mathrm{SI}_{3} \mathrm{~N}_{4}$ coated Mo substrates, both with and without pre-etching.

Single crystal ribbons sawn from a float zone ingot have been re-grown and will be used for solar cell fabrication as well. These will serve as controls and should provide an additional estimate of the potential of RTR grown silicon for solar cells. These will be processed together with re-grown CVD and Czochralski ribbons. 
To date we have only reported on solar cells made by conventional diffusion processes (both mesa and planar). Ion implantation is now being used for solar cell fabrication in parallel with the diffusion process. This is a much faster means of making cells and requires less handling. It is expected that these two techniques will continue to be used in parallel in the future. 


\section{$9.0 \quad$ NEW TECHNOLOGY}

The following New Technology items have been developed on this program:

1. Description.- Polygon Scanner System

Innovator - Dr. Richard Gurtler

Progress Reports - Technical Progress Report No. 14, October 1977

Pages - 1, 10, 11A and 11

2. Description - Hemispherical Reflector to Improve Effective

Absorptinn roneffirient of Liquid Silicon

Innovator - Dr. Ricahrd Gurtler

Progress Reports - Technical Quarterly Report No. 7,

Motorola Report 2256/9, January 1, 1978 - March 31, 1978,

Pages - Appendix Pages 11 - 13.

3. Description - Dendritic Growth on RTR Silicon

Innovator: Dr: A. Baghdadi, R. J. Ellis, Dr. R. W. Gurtler

Progress Reports: Technical Quarterly Report No. 6, Motorola Report

No. 2256/8, October 10 - December 31, 1977.

Pages $14-23$.

4. Description - Controlled. Dendritic Growth

Innovator: Dr. A. Baghdadi and Mr. R. J. Ell is

Progress Reports: Monthly Report No. 21, August 1978,

JPL.DOE No. 954376.

Page 1.

5. Description - Coated Substrates for Silicon Deposition

Innovator: Dr. R. Legge

Progress Reports: Monthly Report No. 20, July 1978,

JPL/DOE NO. 954376.

Page 20. 


\section{MILESTONE CHART}

Contract No. 954376

MOTOROLA PROJECT NO.. 2319-2325

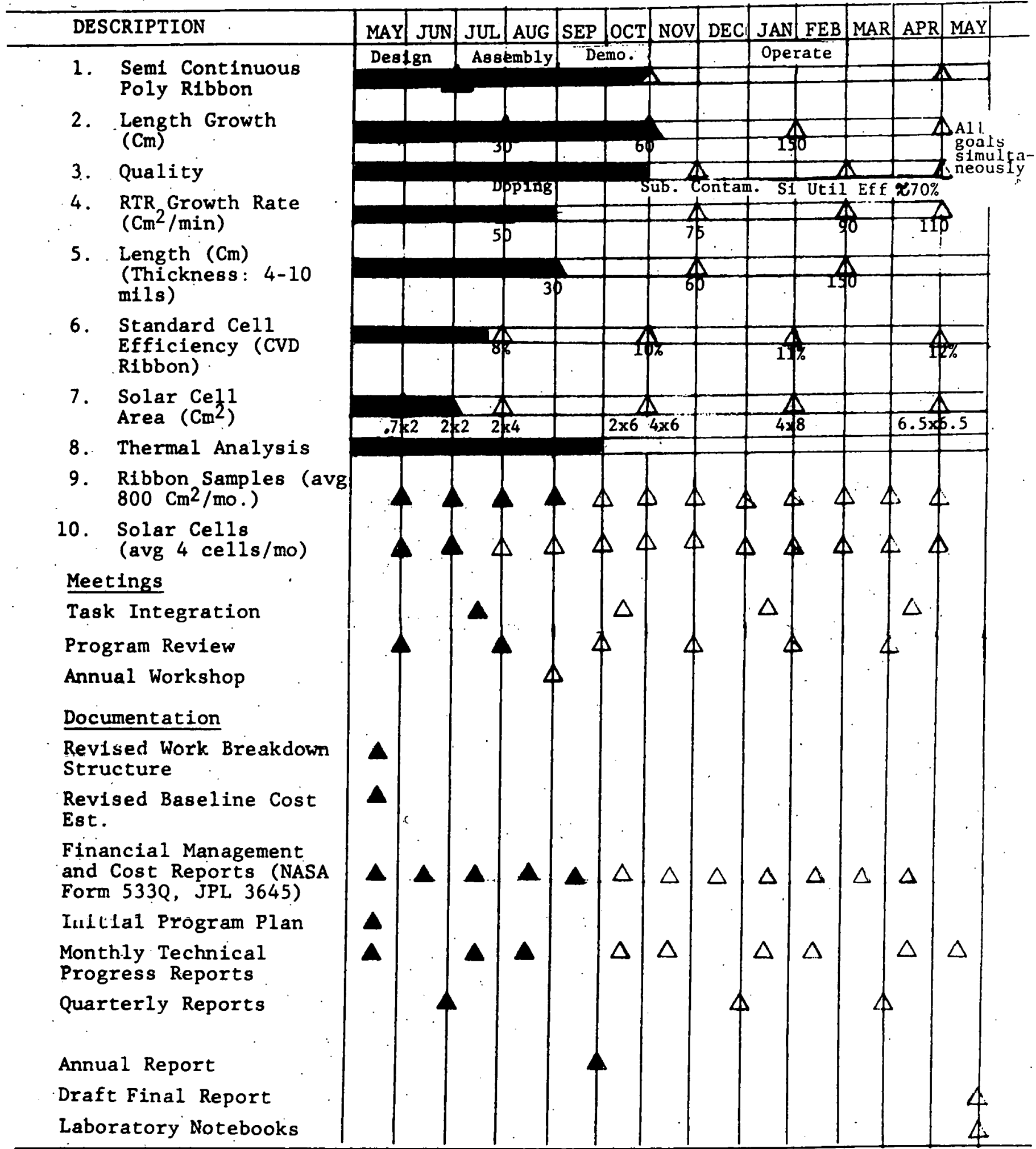

